\title{
Modeling regional air quality and climate: improving organic aerosol and aerosol activation processes in WRF/Chem version 3.7.1
}

\author{
Khairunnisa Yahya ${ }^{1}$, Timothy Glotfelty ${ }^{1}$, Kai Wang ${ }^{1}$, Yang Zhang ${ }^{1}$, and Athanasios Nenes ${ }^{2,3,4,5}$ \\ ${ }^{1}$ Department of Marine, Earth, and Atmospheric Sciences, North Carolina State University, Raleigh, NC, USA \\ ${ }^{2}$ School of Earth and Atmospheric Sciences, Georgia Institute of Technology, Atlanta, GA, USA \\ ${ }^{3}$ School of Chemical and Biomolecular Engineering, Georgia Institute of Technology, Atlanta, GA, USA \\ ${ }^{4}$ Institute of Environmental Research \& Sustainable Development, National Observatory of Athens, Athens, Greece \\ ${ }^{5}$ Institute for Chemical Engineering Science, Foundation for Research and Technology-Hellas, Patra, Greece
}

Correspondence to: Yang Zhang (yzhang9@ncsu.edu)

Received: 23 November 2016 - Discussion started: 6 December 2016

Revised: 16 May 2017 - Accepted: 18 May 2017 - Published: 27 June 2017

\begin{abstract}
Air quality and climate influence each other through the uncertain processes of aerosol formation and cloud droplet activation. In this study, both processes are improved in the Weather, Research and Forecasting model with Chemistry (WRF/Chem) version 3.7.1. The existing Volatility Basis Set (VBS) treatments for organic aerosol (OA) formation in WRF/Chem are improved by considering the following: the secondary OA (SOA) formation from semivolatile primary organic aerosol (POA), a semi-empirical formulation for the enthalpy of vaporization of SOA, and functionalization and fragmentation reactions for multiple generations of products from the oxidation of VOCs. Over the continental US, 2-month-long simulations (May to June 2010) are conducted and results are evaluated against surface and aircraft observations during the Nexus of Air Quality and Climate Change (CalNex) campaign. Among all the configurations considered, the best performance is found for the simulation with the 2005 Carbon Bond mechanism (CB05) and the VBS SOA module with semivolatile POA treatment, $25 \%$ fragmentation, and the emissions of semi-volatile and intermediate volatile organic compounds being 3 times the original POA emissions. Among the three gas-phase mechanisms (CB05, CB6, and SAPRC07) used, CB05 gives the best performance for surface ozone and $\mathrm{PM}_{2.5}$ concentrations. Differences in SOA predictions are larger for the simulations with different VBS treatments (e.g., nonvolatile POA versus semivolatile POA) compared to the simulations with different gas-phase mechanisms. Compared to the simulation with $\mathrm{CB} 05$ and the default SOA module, the simula-
\end{abstract}

tions with the VBS treatment improve cloud droplet number concentration (CDNC) predictions (normalized mean biases from $-40.8 \%$ to a range of -34.6 to $-27.7 \%$ ), with large differences between CB05-CB6 and SAPRC07 due to large differences in their $\mathrm{OH}$ and $\mathrm{HO}_{2}$ predictions. An advanced aerosol activation parameterization based on the Fountoukis and Nenes (2005) series reduces the large negative CDNC bias associated with the default Abdul Razzak and Ghan (2000) parameterization from $-35.4 \%$ to a range of -0.8 to $7.1 \%$. However, it increases the errors due to overpredictions of CDNC, mainly over the northeastern US. This work indicates a need to improve other aerosol-cloudradiation processes in the model, such as the spatial distribution of aerosol optical depth and cloud condensation nuclei, in order to further improve CDNC predictions.

\section{Introduction}

The Intergovernmental Panel on Climate Change (IPCC) report on the AR5 scenario considers the aerosol radiative forcing $(\mathrm{RF})$ to be the dominant source of uncertainty contributing to the overall uncertainty in the net industrial-era RF calculations (Myhre et al., 2013). Despite the inclusion of more aerosol processes in the current generation of atmospheric models, differences between atmospheric models and observations continue to persist. Aerosols affect the climate through the direct effect, by absorbing or scattering radiation, or the indirect effect, by acting as cloud condensation nu- 
clei (CCN). According to Hallquist et al. (2009), the formation of inorganic particulates such as sulfate, nitrate, and ammonium are well understood; however, there are large uncertainties in the formation of secondary organic aerosol (SOA). As a result, current models do not have a comprehensive treatment of organic aerosol (OA), which usually result in an underprediction of OA concentrations (Hodzic et al., 2010; Jathar et al., 2011; Bergstrom et al., 2012), due to missing key precursors and processes in OA formation (Ahmadov et al., 2012). Some of the missing key precursors in most models include semi-volatile primary organic aerosol (POA), long-chain $n$-alkanes, polycyclic aromatic hydrocarbons, and large olefins that have lower volatilities compared to traditional SOA precursors (Chan et al., 2009). Also, the organic carbon (OC) component of the radiative forcing in the IPCC AR5 report does not include SOA because the formation is dependent on a number of factors that are not currently sufficiently quantified (Myhre et al., 2013). However, SOA can form a significant percentage of total OA (up to $95 \%$ in rural areas) (Zhang et al., 2007). Another large source of uncertainty is the quantification of clouds as well as aerosolcloud interactions due to incomplete or inaccurate representations of these processes in climate models (Boucher et al., 2013). A major process in cloud formation from aerosol is aerosol activation, which involves the condensational growth of aerosols in a cooling air parcel until maximum supersaturation, and some of the wet particles reach a critical radius where they are then able to grow spontaneously into cloud droplets (Ghan et al., 2011). Various approaches have been developed to reduce the uncertainties associated with OA and aerosol activation treatments in climate models. Those treatments are reviewed in the following section.

\subsection{VBS treatments and sensitivity to different gas-phase chemical mechanisms in regional and global models}

Unlike inorganic aerosols such as sulfate, the physical and chemical properties of OA dynamically evolve with age (Jimenez et al., 2009). The traditional approach to modeling SOA is to assume that each VOC precursor forms several surrogate compounds (Odum et al., 1996). However, the traditional method has several shortcomings, for example, two products are needed for each VOC precursor, causing this method to be computationally expensive if many VOC precursors are treated in the model (Murphy and Pandis, 2009). The assumption that the products are unreactive also does not reflect the dynamic nature of the first-generation products from the oxidation of VOCs that can undergo successive oxidation steps to further produce lower volatility products (Jimenez et al., 2009). The volatility basis set (VBS) is a framework developed by Donahue et al. (2006), which is able to simulate gas-phase partitioning and multiple generations of gas-phase oxidation of organic vapors. This approach addresses the shortcomings of the traditional SOA modeling approach as it can cover the complete volatility range of OA compounds (Murphy and Pandis, 2009).

Table 1 summarizes some of the VBS treatments from current regional and global models. The VBS treatment has been implemented into a number of regional models such as the Weather, Research and Forecasting model with Chemistry (WRF/Chem; Shrivastava et al., 2011; Ahmadov et al., 2012), the Particulate Matter Comprehensive Air Quality Model with extensions (PMCAMx; Lane et al., 2008; Donahue et al., 2009; Murphy and Pandis, 2009), and CHIMERE (Hodzic et al., 2010). It has also been implemented in global models such as GISS II' GCM (Farina et al., 2010; Jathar et al., 2011) and the Community Earth System Model (CESM; Shrivastava et al., 2015). Different studies define the classifications of the organic species slightly differently. Donahue et al. (2009) defined primary organic vapors with effective saturation concentrations $\left(C^{*}\right)$ of $10^{-2}$ $10^{-1}, 10^{0}-10^{2}$, and $10^{3}-10^{6} \mu \mathrm{g} \mathrm{m}^{-3}$ at $298 \mathrm{~K}$ as volatility organic compounds (LVOCs), semi-volatile organic compounds (SVOCs), and intermediate volatility organic compounds (IVOCs), respectively. Shrivastava et al. (2011) and Jathar et al. (2011) defined primary organic vapors with $C^{*}$ values of $10^{-2}-10^{3}$ and $10^{4}-10^{6} \mu \mathrm{g} \mathrm{m}^{-3}$ to be SVOCs and IVOCs, respectively. All those studies defined VOCs as gas-phase organic species with $C^{*}$ larger than $10^{6} \mu \mathrm{g} \mathrm{m}^{-3}$ at $298 \mathrm{~K}$.

The traditional emission inventories used in the chemical transport models consist of VOCs but not SVOCs or IVOCs as both SVOCs and IVOCs are difficult to measure. This is most likely because SVOCs and IVOCs tend to evaporate at high temperatures from combustion sources (Donahue et al., 2009). As the traditional SOA approach usually underpredicts the SOA concentration, the addition of the SVOC and IVOC emissions on top of the existing VOC emissions in most emission inventories can improve model performance. To account for the missing key precursors in OA formation, SVOC and IVOC emissions are usually estimated as a factor of existing POA emissions in current emission inventories. For example, Shrivastava et al. (2011) estimated the sum of all SVOC and IVOC precursors to be 7.5 times the mass of the traditional POA emissions inventory over Mexico City, but indicated that the scaling factor of 3 for SVOC emissions based on the POA emissions is poorly constrained. Shrivastava et al. (2008) and Jathar et al. (2011) assumed that SVOC emissions are represented by the traditional emission inventory while IVOC emissions are 1.5 times the traditional emission inventory. Pye and Seinfeld (2010) assumed that SVOC emissions are a subset of traditional POA emission inventories, and their POA emissions were scaled up by $27 \%$ on a global scale. IVOC emissions are assumed to be spatially distributed, similar to naphthalene, and are predicted to be roughly a factor of half of global POA emissions. Tsimpidi et al. (2010) assumed that the IVOC emissions are 1.5 times the traditional POA emission inventory and are assigned to the fourth volatility bin with $C^{*}=10^{5} \mu \mathrm{g} \mathrm{m}^{-3}$. For comparison, 


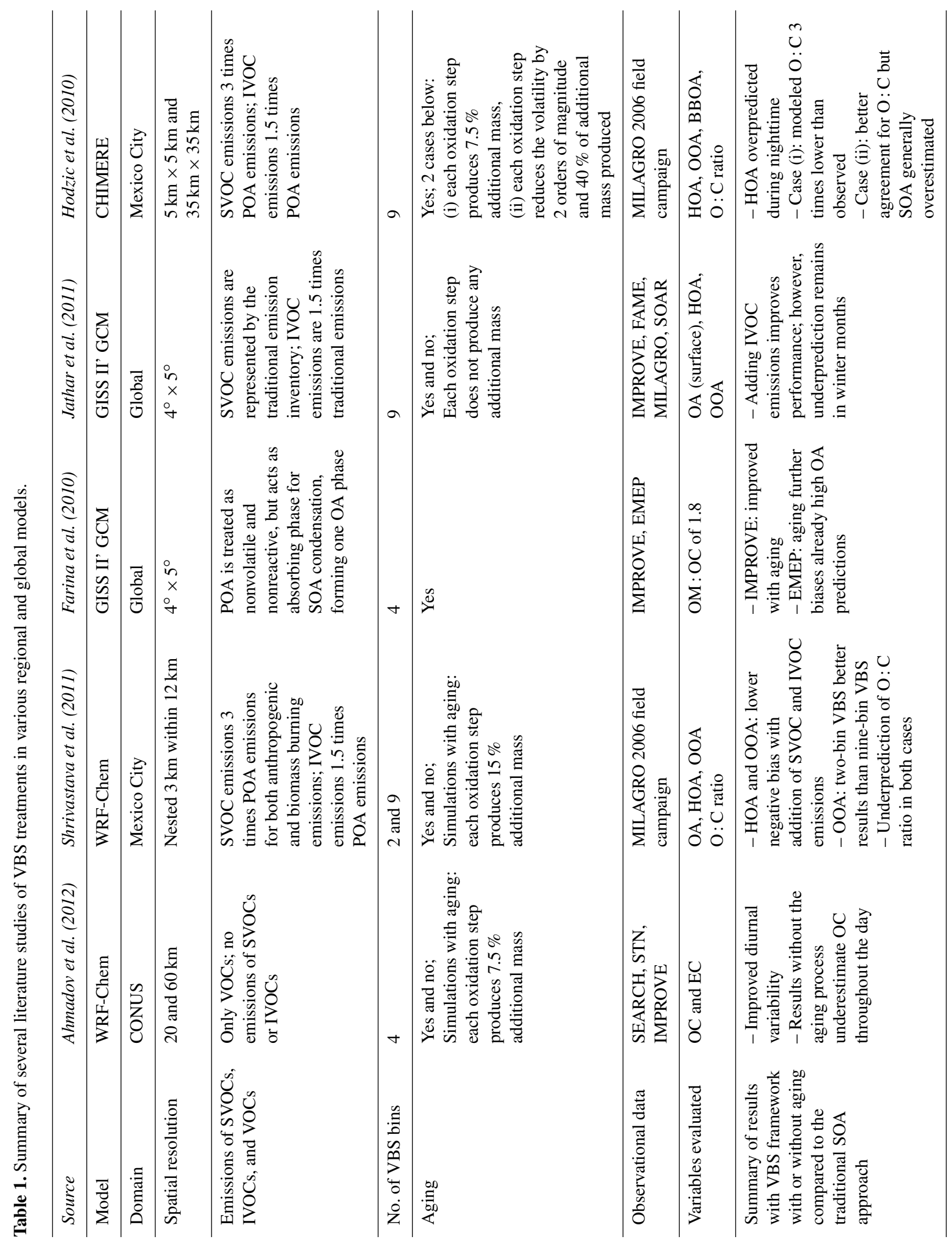




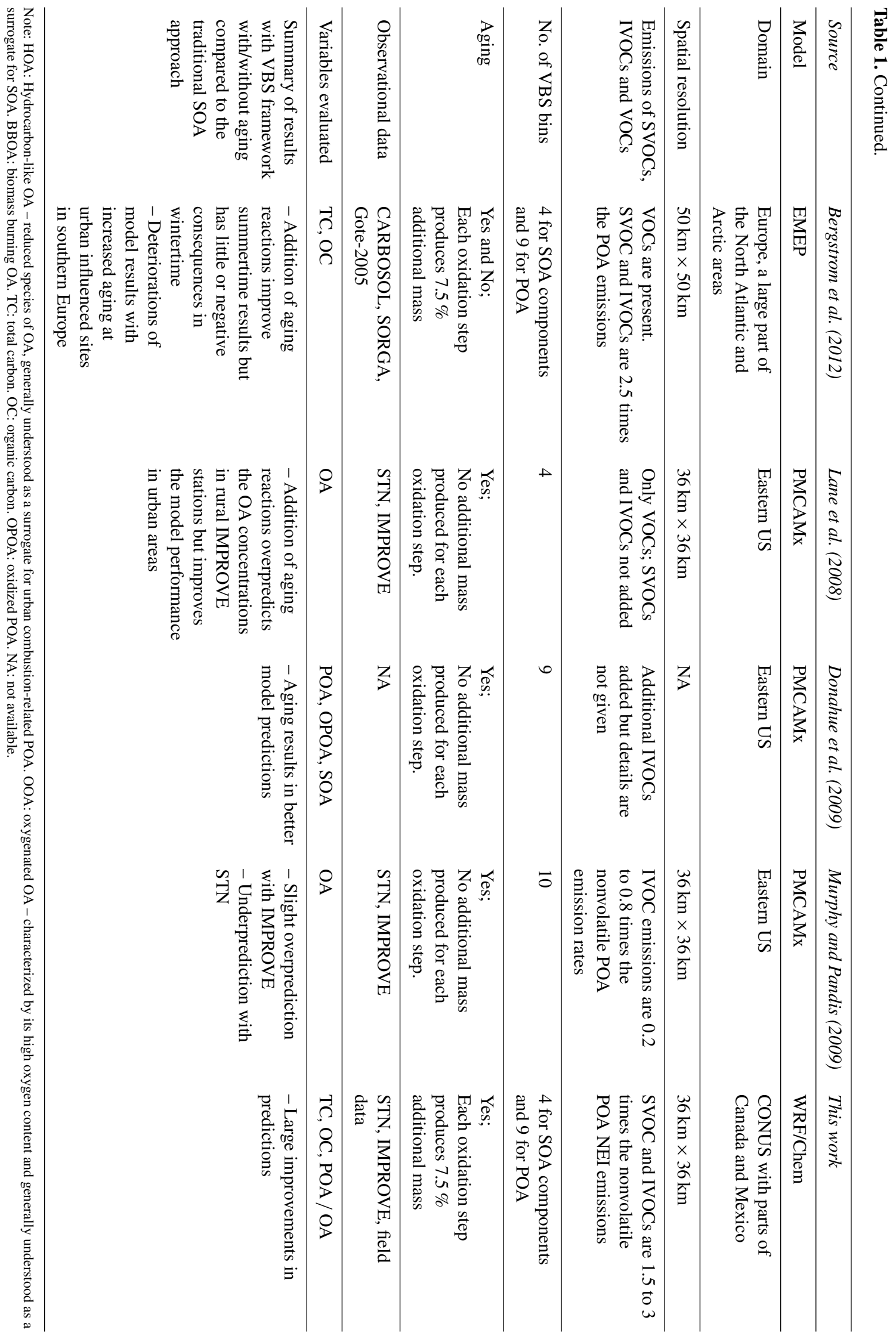


some studies such as Ahmadov et al. (2012) and Bergstrom et al. (2012) used the VBS approach for OA modeling but did not include additional SVOC emissions. There are also differences in the volatility distribution used in the literature. Shrivastava et al. (2008) and Jathar et al. (2011) found that moving half the mass of SVOC from all bins to the lowest bin from the traditional "diesel exhaust" volatility distribution of Robinson et al. (2007) produced the lowest errors in simulated OA on an annual-average basis.

The number of bins used can also result in differences in simulated SOA concentrations. Shrivastava et al. (2011) showed that the two-species VBS performed better than the nine-species VBS in modeling oxygenated organic aerosol (OOA) and gave the closest agreement to the OOA calculated by the positive matrix factorization (PMF) method. This indicates that SOA may be less volatile compared to the volatility distribution in the nine-species VBS, which allows for evaporation of SOA with dilution (Shrivastava et al., 2011).

There are uncertainties in the amount of oxygen added for each oxidation step. This factor can influence the $\mathrm{O}: \mathrm{C}$ ratio used for the model evaluation. $\mathrm{O}: \mathrm{C}$ predictions from models need to be improved by including fragmentation reactions (which could lead to an increase in $\mathrm{O}: \mathrm{C}$ ratios) and improving emission estimates (Shrivastava et al., 2011). Different rate constants can also result in different predictions of SOA concentrations. For example, Farina et al. (2010) showed that the use of a $k$ value of $1 \times 10^{-12} \mathrm{~cm}^{3}$ molecule ${ }^{-1} \mathrm{~s}^{-1}$ (compared to the default $k$ value of $10 \times 10^{-12} \mathrm{~cm}^{3}$ molecule $\mathrm{e}^{-1} \mathrm{~s}^{-1}$ ) resulted in a reduced aged SOA formation by $71 \%$. Hodzic et al. (2010) also showed a case study based on Grieshop et al. (2009) in which each oxidation step reduced the volatility of the SVOC and IVOC vapors by two orders of magnitude, and each successive oxidation step produced a $40 \%$ increase in mass due to the addition of oxygen. This case is inconclusive in urban areas - a larger bias along with a higher correlation coefficient compared to the more common case where each oxidation step reduced the volatility by 1 order of magnitude with a $7.5 \%$ increase in mass. However, the model performed worse (with larger bias and lower correlation coefficient) in suburban areas.

The aging process improves model performance in general in the United States (US) but deteriorates the performance in several parts of Europe. Accounting for the aging process of OA will increase the OA concentrations and improve model results in the US, where OA is usually underpredicted, but increase the model bias for OA in several parts of Europe, where OA concentrations are overpredicted (Farina et al., 2010; Bergstrom et al., 2012).

Shrivastava et al. (2013) studied the effects of the fragmentation and functionalization in VBS. Functionalization increases the mass of OA for each successive oxidation step, while fragmentation reduces the mass for each oxidation step. One such case includes simulating first-order effects of the fragmentation and functionalization processes in VBS by assuming functionalization of $100 \%$ of organic vapors for the first two generations of oxidation and both fragmentation and functionalization for the third and higher generations of oxidation. The fragmentation reduces the SOA concentrations drastically. For example, Shrivastava et al. (2013) showed that peak SOA concentrations can be reduced by factors of 2 to 4 for a $1 \mathrm{~h}$ example on 10 March 2006 at 21:00 UTC over the Mexico City Plateau.

The VBS framework for OA modeling in the latest version of WRF/Chem, v3.7.1, is coupled with several gasphase mechanisms including the 2005 Carbon Bond Mechanism (CB05; Yarwood et al., 2005), the Model for Ozone and Related chemical Tracers version 4 (MOZART-4; Emmons et al., 2010), the Regional Atmospheric Chemistry Model (RACM; Stockwell et al., 1997), and the 1999 version of the Statewide Air Pollution Research Centre (SAPRC99) mechanism (Carter, 2000). Different gas-phase mechanisms have different lumpings or groupings for VOCs, which will affect OA formation. For example, VOCs are lumped according to their carbon bonds (e.g., single or double bond) in CB05 (Yarwood et al., 2005) while VOCs in SAPRC99 (Carter, 2000) are lumped according to their $\mathrm{OH}$ reactivities. A number of studies examined the differences in predicting $\mathrm{O}_{3}$ concentrations due to different gas-phase mechanisms (e.g., Luecken et al., 2008; Li et al., 2012; Shearer et al., 2012; Zhang et al., 2012), but fewer studies reported the impact of different gas-phase mechanisms on modeling SOA and $\mathrm{PM}_{2.5}$ concentrations (Kim et al., 2011; Zhang et al., 2012). SAPRC99 has more detailed organic chemistry compared to CB05. SAPRC99 has been updated to SAPRC07 (and recently, to SAPRC11) based on newly available information regarding the reactions and influence of individual VOCs on $\mathrm{O}_{3}$, as well as evaluations against chamber experiments (Carter, 2010). In addition, SAPRC07 has reformulated reactions of peroxy radicals so that the effects of changes in nitrogen oxides $\left(\mathrm{NO}_{x}\right)$ on organic product formation is more accurately represented. SAPRC07 has the most extensive set of VOC species and reactions, compared to CB05 and the Carbon Bond version 6 (CB6). Shearer et al. (2012) reported that a condensed version of SAPRC07 predicted lower $\mathrm{O}_{3}$ and $\mathrm{OH}$ concentrations in central California compared to SAPRC99 due to a decreased reaction rate coefficient in the reaction of $\mathrm{OH}$ and $\mathrm{NO}_{2}$ to form $\mathrm{HNO}_{3}$. $\mathrm{Li}$ et al. (2012) also showed that predicted $\mathrm{O}_{3}$ concentrations from SAPRC07 were lower than those of SAPRC99 by up to $20 \%$ over Texas. The same study also reported that SAPRC07 gave lower $\mathrm{OH}$ concentrations due to differences in the reaction rate constants in the reactions of $\mathrm{O}^{1} \mathrm{D}$ and $\mathrm{H}_{2} \mathrm{O}$ between SAPRC07 and SAPRC99. Luecken et al. (2008) reported that SAPRC99 gave higher $\mathrm{O}_{3}$ concentrations compared to $\mathrm{CB} 05$ on average; however, the differences vary with locations, $\mathrm{VOC} / \mathrm{NO}_{x}$ ratios, and the concentrations of precursor pollutants. This is consistent with the results from Zhang et al. (2012), which predicted that SAPRC99 us- 
ing WRF/Chem with the Model of Aerosol, Dynamics, Reaction, Ionization and Dissolution (WRF/Chem-MADRID) produced the highest $\mathrm{O}_{3}$ mixing ratios in July at the Southeastern Aerosol Research and Characterization (SEARCH) sites. The CB6 (Yarwood et al., 2010) is an updated version of CB05, with improved kinetic and photolysis data; additional explicit species for long-lived and abundant organic compounds including propane, acetone, benzene, and acetylene; and revised isoprene and aromatics chemistry from CB05. Yarwood et al. (2010) showed that CB6 produces higher daily maximum $8 \mathrm{~h} \mathrm{O} 3$ compared to $\mathrm{CB} 05$ over Los Angeles for one episode day in August with the highest observed $\mathrm{O}_{3}$ mixing ratios. $\mathrm{CB} 6$ was also shown to produce substantially higher $\mathrm{OH}$ concentrations ( 25 to $50 \%$ higher at midday over large areas) over the eastern US compared to CB05 over a few days in June 2006. A summary of the main characteristics of CB05, CB6, and SAPRC07 gas-phase mechanisms are listed in Table 2.

\subsection{Description of aerosol activation parameterizations}

Ghan et al. (2011) provided a comprehensive review on various aerosol activation treatments in current climate models. Two main types of parameterizations are commonly used: the Abdul-Razzak and Ghan (2000; AR-G00) and the Fountoukis and Nenes (2005; FN05) and associated updates described in Barahona et al. (2010) and Morales Betancourt and Nenes (2014). AR-G00 uses multiple lognormal or sectional distributions to approximate the aerosol size distribution. It uses the Kohler theory to relate the aerosol size distribution and composition to the number of aerosols activated as a function of maximum supersaturation $\left(S_{\max }\right)$. The complex function involving $S_{\max }$ is parameterized based on the standard deviation $\sigma$ from a large number of numerical solutions using a cloud parcel model. The number and mass activated are particles with critical supersaturation less than $S_{\max }$. It also accounts for particle growth before and after the particles are activated. However, the Abdul Razzak and Ghan (2000; ARG00) treatment does not explicitly represent kinetic limitations which tend to affect smaller or larger particles (with diameters far from their critical size). Very small particles tend to lose water when supersaturation declines, as they never exceed the critical supersaturation for that particle size, and very large particles may not have achieved the critical size before $S_{\max }$ is reached (Ghan et al., 2011). Kinetic limitations refer to the (i) inertial mechanism - where particles with large dry diameters grow to be as large as activated particles but have not been activated themselves, these particles should be considered together with activated particles; (ii) evaporation mechanism - where particles with high critical supersaturation evaporate before reaching their critical diameters; and (iii) deactivation mechanism - where initially activated particles that are deactivated to interstitial aerosols when the parcel supersaturation falls below the equilibrium supersaturation (Nenes et al., 2001). Neglecting kinetic limitations performs well for all conditions except in highly polluted areas (Ghan et al., 2011). In urban and highly polluted cases, many particles fail to be activated due to strong evaporation and deactivation processes (Nenes et al., 2001). Explicitly accounting for kinetic limitations reduces CDNC at low updraft velocity (Ghan et al., 2011).

The FN05 scheme improved the ARG00 scheme by solving $S_{\max }$ analytically (with the exception of kinetically limited particles) using a so-called "population splitting" method. In addition, FN05 took into account the kinetic limitations, as well as the influence of gas kinetics on water vapor diffusivity (Ghan et al., 2011). The other improved treatments built on top of the FN05 scheme include the entrainment of ambient air, which could reduce the supersaturation of the updraft (Barahona and Nenes, 2007; BN07), therefore reducing CDNC; the adsorption of water vapor onto insoluble particles by Kumar et al. (2009; KU09) based on a modified Frenkel-Halsey-Hill (FHH) adsorption theorem (which will increase $\mathrm{CDNC}$ ); the growth of giant cloud condensation nuclei (CCN) (Barahona et al., 2010, BA10) by introducing an additional condensation rate term to account for condensation of giant CCN (which will reduce CDNC); as well as the modification of the original population splitting concept in FN05 and BA10 by Morales Betancourt and Nenes (2014; MN14) by better accounting for the size of inertially limited $\mathrm{CCN}$, and removing a discontinuity in the calculation of the surface area of cloud droplets.

The parameterization of Abdul Razzak and Ghan (2000) (ARG00) is used as the default aerosol activation module in WRF/Chem. It is not linked to the microphysics module or cumulus parameterization in WRF or WRF/Chem. However, for WRF/Chem, the CDNC generated in ARG00 is passed to the microphysics scheme, i.e., the Morrison two-moment microphysics scheme selected in this work.

\subsection{Motivations and objectives}

The online-coupled meteorology and chemistry model, WRF/Chem, has recently been applied for air quality and climate modeling on a decadal scale (Yahya et al., 2016, 2017). WRF/Chem can also simulate aerosol direct and indirect feedbacks, which are important considerations for climate modeling. However, as mentioned previously, the representations of OA and aerosol-cloud interactions in current regional and global climate models are subject to large uncertainties. In particular, while the VBS framework in WRF/Chem significantly improves SOA performance (Wang et al., 2015), it lacks the semi-volatile POA treatment, as well as fragmentation processes (Shrivastava et al., 2013). The first objective of this study is to reduce uncertainties associated with OA predictions by improving the existing VBS module in WRF/Chem and identifying the best gasphase chemical mechanism to drive the VBS module for the most accurate OA predictions. The impact of the improved 


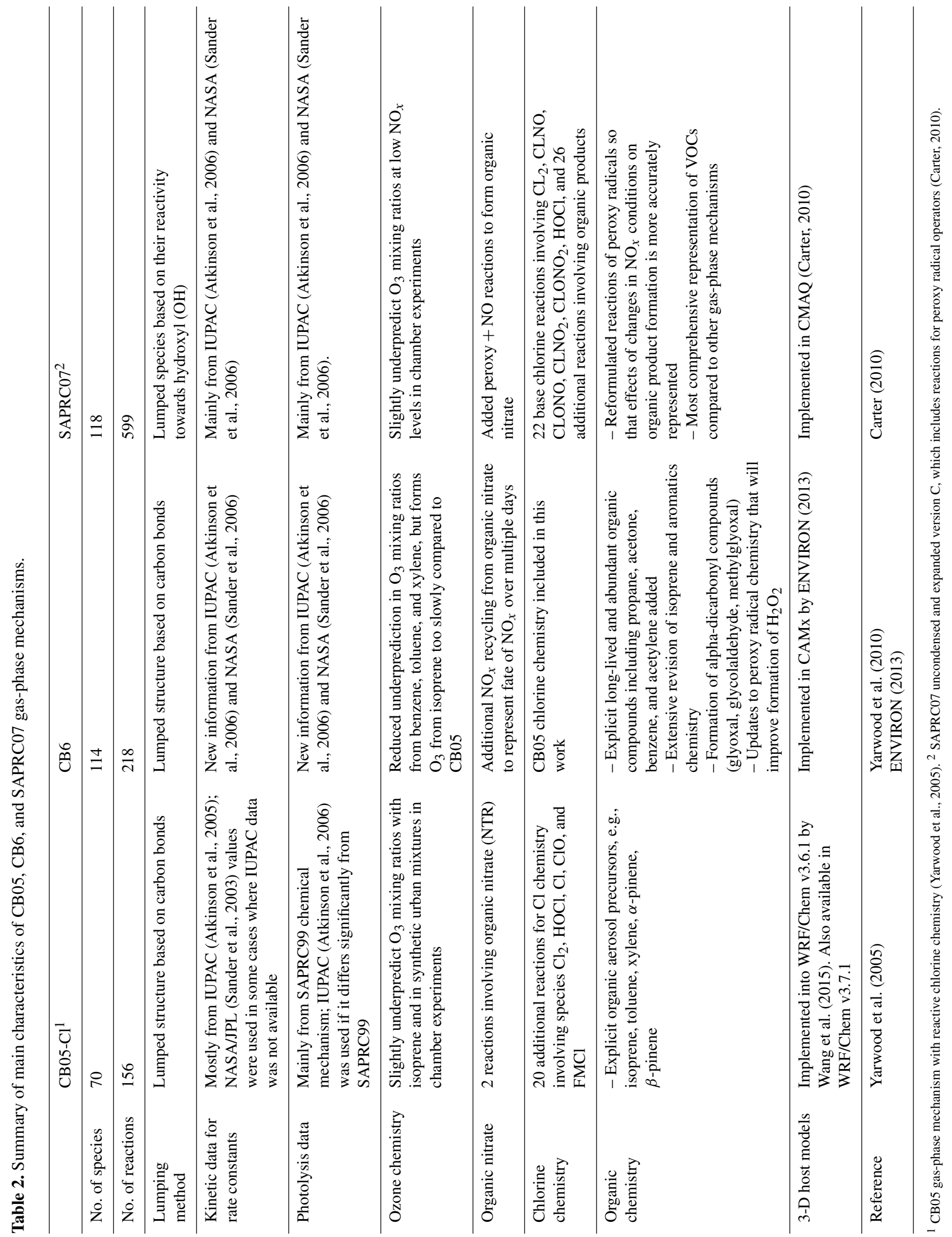


OA predictions on CDNC in WRF/Chem will be quantified. The second objective is to incorporate an improved aerosol activation parameterization based on the FN05 series into WRF/Chem to study its impacts on CDNC predictions.

\section{Model configuration, evaluation protocol, and observational datasets}

\subsection{Model setup and inputs}

The model used in this study is a modified version of WRF/Chem v3.7.1 as described by Wang et al. (2015). The 2005 Carbon Bond gas-phase mechanism (CB05) of Yarwood et al. (2005), with additional chlorine chemistry, is coupled with the Modal for Aerosol Dynamics in Europe - Secondary Organic Aerosol Model (MADE/SORGAM) (Anchorman et al., 1998; Schell et al., 2001) and the Volatility Basis Set (MADE/VBS) (Ahmadov et al., 2012). The CB05-VBS option has also been coupled to existing model treatments including the aerosol direct effect, the aerosol semidirect effect on photolysis rates of major gases, and the aerosol indirect effect on CDNC and resulting impacts on shortwave radiation. The physics options used in WRF/Chem include the rapid and accurate radiative transfer model for GCM (RRTMG) for both shortwave and long-wave radiation, the Yonsei University (YSU) planetary boundary layer (PBL) scheme (Hong et al., 2006; Hong, 2010), the Morrison et al. (2009) double moment microphysics scheme, as well as the multi-scale Kain-Fritsch (MSKF) cumulus parameterization scheme (Zheng et al., 2016). Aqueous-phase chemistry module (AQCHEM) for both resolved and convective clouds is based on a similar AQCHEM module in CMAQv4.7 from Sarwar et al. (2011). The anthropogenic emissions used are from the 2010 emissions based on the 2008 US Environmental Protection Agency (US EPA) National Emissions Inventory (NEI) from the Air Quality Model Evaluation International Initiative (AQMEII) project (Pouliot et al., 2015). Dust emissions are based on the Atmospheric and Environmental Research Inc. and Air Force Weather Agency (AER/AFWA) scheme (Jones and Creighton, 2011). Emissions from sea salt are generated based on the scheme of Gong et al. (1997). Biogenic emissions are simulated online by the Model of Emissions of Gases and Aerosols from Nature v2.1 (MEGAN2.1) (Guenther et al., 2006).

The chemical initial and boundary conditions (ICONs and BCONs) come from the modified CESM/CAM version 5.3 with updates by Gantt et al. (2014), He and Zhang (2014), and Glotfelty et al. (2017). The meteorological ICONs and BCONs are from the National Center for Environmental Protection Final Reanalyses (NCEP FNL) dataset, which is available every $6 \mathrm{~h}$. The chemical fields are also allowed to run continuously while the meteorology is reinitialized every 5 days. The simulations are performed at a horizontal resolution of $36 \mathrm{~km}$ with $148 \times 112$ horizontal grid cells over the CONUS domain and parts of Canada and Mexico, and a vertical resolution of 34 layers from the surface to $100 \mathrm{hPa}$.

A number of sensitivity simulations are designed to identify the model configuration with results that are in the closest agreement to observations as well as the realistic model treatments of OA that are the closest to atmospheric processes. The baseline and sensitivity simulations are conducted from May to June 2010, during which the Nexus of Air Quality and Climate Change (CalNex) campaign was held in Bakersfield and Pasadena, California. The first 10 days, from 1 to 10 May, are considered to be the spin-up period.

\subsection{Model evaluation protocol and available measurements}

Statistical measures including the mean bias (MB), correlation coefficient (Corr), normalized mean bias (NMB) and normalized mean error (NME) (Yu et al., 2006) are used to evaluate the simulations against observational data. Observational data are available for organic carbon (OC) and total carbon (TC) from the Speciated Trends Network (STN) and the Interagency Monitoring for Protected Visual Environments (IMPROVE). While both OC and TC from IMPROVE are used for model evaluation, only TC data from STN are used, as STN uses the thermo-optical transmittance protocol for OC that is different from the one used by IMPROVE (Zhang et al., 2012). In addition, the measurements for STN OC are not blank corrected for carbon on the background filter (Wang and Zhang, 2012). The OA / OC ratios vary across locations in the continental US (CONUS) depending on whether the OA is dominated by secondary formation (Aitken et al., 2008) or it contains more aliphatic hydrocarbons (Turpin and Lim, 2001). In this study, two ratios, 1.4 and 2.1, are used to convert simulated OA to OC based on a number of studies in the literature (Turpin and Lim, 2001; Aitken et al., 2008; Xu et al., 2015). As the simulations are based on CONUS with varying OA properties (less or more oxidized OA), the use of two OA / OC ratios can represent the different types of OA present for all locations in the US. Spatial plots, time series plots at specific sites, and overlay plots are used to evaluate model performance. The IMPROVE sites chosen for the time series plots include the visibility-protected areas in Brigantine National Wildlife Refuge (NWR), NJ, Death Valley National Park (NP), CA, Swanqwarter National Wildlife Refuge (NWR), NC, and the Tallgrass Prairie National Preserve, KS. The Brigantine NWR is a tidal wetland and has a shallow bay, the Death Valley NP is a desert, and the Swanqwarter NWR is a coastal brackish marsh. The time series plots are made at four STN sites including two urban sites (in Washington, DC, and Boise, ID), one industrial site (in Tampa, FL), and one rural/agricultural site (in Liberty, KS). SOA, hydroxyl radical $(\mathrm{OH})$, and hydroperoxy radical $\left(\mathrm{HO}_{2}\right)$ data are also available for May to June 2010 as part of the CalNex campaign (Kleindienst et al., 2012; Lewandowski et al., 2013) in Bak- 
ersfield, CA, and Pasadena, CA, which are both urban locations. The Bakersfield sampling site is located between the city center and areas of agricultural activity, while the Pasadena site is located at the California Institute of Technology campus between the Los Angeles metropolitan area to the southwest and mountains in the north (Baker et al., 2015).

POA / OA ratios are also used to evaluate the performance of the model. A number of studies have reported observed POA / OA ratios which range from 15 to $40 \%$ over CONUS. For example, over the southeastern US, hydrocarbon-like OA (HOA) and cooking OA are found to contribute to 21$38 \%$ of total OA in urban sites (Xu et al., 2015). HOA and oxygenated OA (OOA) are found to account for 34 and $66 \%$ of measured OA from Pittsburgh in September 2002 (Zhang et al., 2005). HOA and cooking OA are assumed to be synonymous with POA, and OOA is assumed to be synonymous with SOA. Particulate matter sampled during August and September 2006 in Houston as part of the Texas Air Quality Study II Radical and Aerosol Measurement Project showed that approximately $32 \%$ of OA comes from HOA (Cleveland et al., 2012). Results from positive matrix factorization analysis from the Pasadena ground site during May and June 2010 showed that the primary components contribute $29 \%$ of the total OA mass (Hayes et al., 2013). Based on Zhang et al. (2007), the percentages of HOA mass at urban sites in Riverside, CA, from mid-July to mid-August 2005, in Houston, TX, from mid-August to mid-September 2000, and in New York City in July 2001 are 15, 38, and 30 \%, respectively. In addition, Zhang et al. (2011) compiled a large number of field campaigns across the globe where the average POA / OA ratios for urban, downwind, and rural/remote areas are found to be $0.42,0.18$, and 0.10 respectively.

For the aerosol activation sensitivity and production simulations, additional variables that will be analyzed in this study include maximum $1 \mathrm{~h}$ and $8 \mathrm{~h} \mathrm{O}_{3}$ against the Clean Air Status and Trends Network (CASTNET) and Air Quality System (AQS), aerosol optical depth (AOD), CDNC, CCN against MODIS.

\section{Model development and improvement}

A number of modifications have been made to the standard version of WRF/Chem model v3.7.1. Those modifications and treatments are described below.

\subsection{OA treatments}

The CB05-VBS treatment in the default WRF/Chem v3.7.1 assumes that POA is nonreactive and nonvolatile. In this study, POA is assumed to be semivolatile, and can undergo gas-particle partitioning, similar to anthropogenic SOA (ASOA) and biogenic SOA (BSOA) in VBS. While the volatility of ASOA and BSOA is represented by 4 bins with $C^{*}$ from $10^{0}$ to $10^{3} \mu \mathrm{g} \mathrm{m}{ }^{-3}$, the POA is distributed into 9 bins, with $C^{*}$ from $10^{-2}$ to $10^{6} \mu \mathrm{g} \mathrm{m}^{-3}$, following the set-up of Shrivastava et al. (2011). The POA is oxidized to form semi-volatile OA, which can also undergo gas-particle partitioning. For the POA, bin-resolved enthalpies of vaporizations are used, ranging from $64 \mathrm{~kJ} \mathrm{~mol}^{-1}$ for the 9th bin to $112 \mathrm{~kJ} \mathrm{~mol}^{-1}$ for the $1 \mathrm{st}$ bin according to Shrivastava et al. (2011). The default enthalpy of vaporization $\left(H_{\mathrm{vap}}\right)$ for SOA in WRF/Chem is $30 \mathrm{~kJ} \mathrm{~mol}^{-1}$ according to Lane et al. (2008). A more accurate alternative is to use the $H_{\text {vap val- }}$ ues calculated from the semi-empirical correlation from Epstein et al. (2010):

$H_{\text {vap }}=-11 \log _{10} C_{300}^{*}+129$.

The values of $H_{\text {vap }}$ from Epstein et al. (2010) are used in a number of sensitivity simulations and final production simulation.

Shrivastava et al. $(2013,2015)$ also implemented several cases of fragmentation and functionalization (FF) processes into VBS. For this study, the FF set-up is similar to the method employed by Shrivastava et al. (2013), with the exception that fragmentation percentages of 10,25 , and $50 \%$ are used in sensitivity simulations. Shrivastava et al. (2013) used fragmentation percentages of $50 \%$ (intermediate fragmentation) and $85 \%$ (high fragmentation) in his simulations over Mexico City. For example, for the $10 \% \mathrm{FF}$ case, $10 \%$ of the mass in the VBS species is functionalized and moved to the next lower volatility bin, $80 \%$ is fragmented and moved to the highest volatility bin, and the remaining $10 \%$ is fragmented and becomes more volatile than the highest volatility bin (i.e., it is lost from the current volatility bins). For the $50 \% \mathrm{FF}$ case, $50 \%$ is functionalized and moved to the next lower volatility bin, $40 \%$ is fragmented and moved to the highest volatility bin, and $10 \%$ is lost.

Zhao et al. (2014) measured IVOCs in Pasadena, CA, during CalNex and found that the concentrations of primary IVOCs are similar to those of single-ring aromatics, and they produce about $30 \%$ of newly formed SOA in the afternoon. With the semivolatile POA and FF cases in this study, additional IVOC and SVOC emissions are added as values that are 3 times as large as the traditional POA emissions from NEI, to account for missing IVOC and SVOC species in the traditional POA emission inventory. The fraction of IVOC and SVOC emissions assigned to each volatility bin is summarized in Table 3.

The mass fraction of organics in each volatility bin determined in laboratory studies also differs significantly according to the sources of organics. For example, May et al. $(2013 \mathrm{a}-\mathrm{c})$ has different volatility distributions of mass fractions of organics for gasoline vehicle exhaust, diesel exhaust, and biomass burning. To take into account the different sources of organic compounds into a single volatility distribution for the purpose of this work, a new volatility distribution is calculated based on the mass fractions reported by Shrivastava et al. (2011) and May et al. (2013a, c) 
Table 3. Factors to calculate SVOC and IVOC emissions from POA emissions from Shrivastava et al. (2011) and May et al. (2013a, c) and newly calculated factors for this study.

\begin{tabular}{|c|c|c|c|c|}
\hline $\begin{array}{l}\log \mathrm{Ci}^{*} \\
\text { at } 298 \mathrm{~K}\end{array}$ & $\begin{array}{c}\text { Normalized } \\
\text { fraction for } \\
\text { stationary } \\
\text { emissions } \\
\text { based on } \\
\text { anthropogenic } \\
\text { emissions from } \\
\text { Shrivastava } \\
\text { et al. (2011) }\end{array}$ & $\begin{array}{c}\text { Fraction } \\
\text { for gasoline } \\
\text { emissions } \\
\text { from May } \\
\text { et al. } \\
\text { (2013a) }\end{array}$ & $\begin{array}{c}\text { Fraction } \\
\text { for biomass } \\
\text { burning } \\
\text { emissions } \\
\text { from May } \\
\text { et al. } \\
(2013 \mathrm{c})\end{array}$ & $\begin{array}{r}\text { New calculated } \\
\text { fraction for } \\
\text { all sources } \\
\text { based on } \\
\text { Shrivastava } \\
\text { et al. }(2011) \text {, } \\
\text { May et al. } \\
\text { (2013a, c), and \% } \\
\text { distribution } \\
\text { of NEI emissions }\end{array}$ \\
\hline-2 & 0.04 & 0.14 & 0.2 & 0.1754 \\
\hline-1 & 0.02 & 0.13 & 0.0 & 0.0141 \\
\hline 0 & 0.03 & 0.15 & 0.1 & 0.0961 \\
\hline 1 & 0.05 & 0.26 & 0.1 & 0.1084 \\
\hline 2 & 0.07 & 0.15 & 0.2 & 0.1799 \\
\hline 3 & 0.11 & 0.03 & 0.1 & 0.0949 \\
\hline 4 & 0.16 & 0.02 & 0.3 & 0.258 \\
\hline 5 & 0.20 & 0.01 & 0.0 & 0.0249 \\
\hline 6 & 0.32 & 0.11 & 0.0 & 0.0483 \\
\hline
\end{tabular}

and the percentages of VOC emissions from various sources from the 2008 NEI. According to the 2008 NEI report (Rao et al., 2013), total VOC emissions from stationary, mobile, and fire (prescribed and wildfire) sources are $\sim 7.6, \sim 5.6$, and $\sim 49.6$ milliont, respectively. The corresponding percentages for VOC emissions are $\sim 12, \sim 9$, and $\sim 79 \%$ for stationary, mobile, and fire sources, respectively. Based on the US EPA (2013), the percentages of diesel emissions from mobile sources are low compared to those from gasoline sources ( $\sim 7 \%$ of total diesel and gasoline sources); they are thus not included in this study.

An example calculation for the mass fraction of the lowest volatility bin for POA and IVOC and SVOC emissions are as follows:

$$
\begin{aligned}
\log C_{-2}^{*}(\text { at } 298 \mathrm{~K}) & =0.04 \times 12 \%+0.14 \times 9 \% \\
& +0.2 \times 79 \%=0.1754
\end{aligned}
$$

where $C_{-2}^{*}$ refers to the lowest volatility bin with a value of $10^{-2} \mu \mathrm{g} \mathrm{m}^{-3} ; 12,9$, and $79 \%$ refer to the percentages for VOC emissions from stationary, mobile, and fire sources, respectively, from NEI; 0.04 refers to the original mass fraction for stationary emissions based on anthropogenic emissions from Shrivastava et al. (2011) for the lowest volatility bin with a value of $10^{-2} \mu \mathrm{g} \mathrm{m}^{-3} ; 0.14$ refers to the original mass fraction for gasoline emissions from May et al. (2013a) for the lowest volatility bin with a value of $10^{-2} \mu \mathrm{g} \mathrm{m}{ }^{-3}$; 0.2 refers to the original mass fraction for biomass burning emissions from May et al. (2013c) for the lowest volatility bin with a value of $10^{-2} \mu \mathrm{g} \mathrm{m}^{-3}$; and 0.1754 refers to the newly calculated mass fraction of POA and IVOC and SVOC emissions for this study. The mass fractions used by Shrivas- tava et al. (2011), May et al. (2013a, c), and this work can be found in Table 3.

\subsection{Gas-phase chemical mechanisms}

Three gas-phase mechanisms are used: CB05, CB6, and SAPRC07. The gas-phase mechanisms for CB6 and SAPRC07 are coupled to the MADE/VBS in WRF/Chem v3.7.1 in this work following the coupling of CB05 with MADE/VBS by Wang et al. (2015). The emissions for all cases are based on the CB05 chemical species from the 2010 emissions based on the 2008 NEI. For SAPRC07, slight modifications had to be made to account for the different VOC species or groups. The mapping of emission species from CB05 to SAPRC07 is based on the grouping of species from emitdb.xls from Henderson et al. (2014) as well as from http://www.cert.ucr.edu/ $\sim$ carter/emitdb/old-emitdb.htm. CB05 emissions are used for the CB6 case, with the exception of the VOCs including propane, benzene, ethyne, acetone, and ketone, which are mapped based on fractions of existing CB05 VOCs according to Yarwood et al. (2010).

In VBS, the SOA precursors for CB6 are similar to those for CB05. The SOA precursors for CB05 (and therefore CB6) are mapped from the default SAPRC99 precursors by Wang et al. (2015). The SAPRC07 SOA precursors follow the existing mapping of SAPRC99-MOSAIC/VBS in $\mathrm{WRF} / \mathrm{Chem}$. The chemical equations and rate parameters from ENVIRON (2013) and Carter (2010) for CB6 and SAPRC07 gas-phase mechanisms, respectively, were included in the "chem/KPP/mechanisms" directory in WRF/Chem. The SAPRC07 gas-phase mechanism im- 
Table 4. Configurations for OA and aerosol activation sensitivity simulations. All simulations except for CB05-SORG-DH contain the VBS treatments for OA.

\begin{tabular}{|c|c|c|c|c|c|c|c|}
\hline Name & $\begin{array}{l}\text { Gas } \\
\text { phase }\end{array}$ & $H_{\text {vap }}$ & VBS & $\mathrm{FF}$ & $\begin{array}{l}\text { POA } \\
\text { emissions }\end{array}$ & $\begin{array}{l}\text { Aerosol } \\
\text { activation }\end{array}$ & $\begin{array}{l}\text { Cumulus } \\
\text { scheme }\end{array}$ \\
\hline CB05-SORG-DH & CB05 & $30 \mathrm{~kJ} \mathrm{~mol}^{-1}$ & $\mathrm{n} / \mathrm{a}$ & $\mathrm{n} / \mathrm{a}$ & Original NEI & ARG00 & Grell-Freitas \\
\hline CB05-VBS-DH & CB05 & $30 \mathrm{~kJ} \mathrm{~mol}^{-1}$ & SOA & $\mathrm{n} / \mathrm{a}$ & Original NEI & ARG00 & Grell-Freitas \\
\hline CB05-POA-DH & CB05 & $30 \mathrm{~kJ} \mathrm{~mol}^{-1}$ & SOA/POA & $\mathrm{n} / \mathrm{a}$ & $1.5 \times$ & ARG00 & Grell-Freitas \\
\hline e CB05-POA & CB05 & Epstein et al. (2010) & SOA/POA & $\mathrm{n} / \mathrm{a}$ & $1.5 \times$ & ARG00 & Grell-Freitas \\
\hline $\mathrm{CB} 05-50 \% \mathrm{FF}$ & CB05 & Epstein et al. (2010) & SOA/POA & $50 \%$ & $1.5 \times$ & ARG00 & Grell-Freitas \\
\hline $\mathrm{CB} 05-10 \% \mathrm{FF}$ & CB05 & Epstein et al. (2010) & SOA/POA & $10 \%$ & $1.5 \times$ & ARG00 & Grell-Freitas \\
\hline CB05-25\%FF & CB05 & Epstein et al. (2010) & SOA/POA & $25 \%$ & $1.5 \times$ & ARG00 & Grell-Freitas \\
\hline CB05-25\%FF-EM3 & CB05 & Epstein et al. (2010) & SOA/POA & $25 \%$ & $3.0 \times$ & ARG00 & Grell-Freitas \\
\hline CB6-25\%FF-EM3 & CB6 & Epstein et al. (2010) & SOA/POA & $25 \%$ & $3.0 \times$ & ARG00 & Grell-Freitas \\
\hline SAPRC07-25\%FF-EM3 & SAPRC07 & Epstein et al. (2010) & SOA/POA & $25 \%$ & $3.0 \times$ & ARG00 & Grell-Freitas \\
\hline $\begin{array}{l}\text { CB05-25\%FF-EM3 } \\
\text { (FN05) }\end{array}$ & CB05 & Epstein et al. (2010) & SOA/POA & $25 \%$ & $3.0 \times$ & FN05 & MSKF \\
\hline $\begin{array}{l}\text { CB05-25\%FF-EM3 } \\
\text { (FN05/BA10) }\end{array}$ & CB05 & Epstein et al. (2010) & SOA/POA & $25 \%$ & $3.0 \times$ & FN05/BA10 & MSKF \\
\hline $\begin{array}{l}\text { CB05-25\%FF-EM3 } \\
\text { (MN14) }\end{array}$ & CB05 & Epstein et al. (2010) & SOA/POA & $25 \%$ & $3.0 \times$ & MN14 & MSKF \\
\hline
\end{tabular}

The suffix "DH" in the case names refers to cases with the default $H_{\mathrm{vap}}$ of $30 \mathrm{~kJ} \mathrm{~mol}^{-1}$, otherwise with the semi-empirical correlation by Epstein et al. (2010). The simulations without the suffix "POA" or "FF" indicate cases with nonvolatile default POA emissions. The suffix "POA" in the case names refers to cases with semivolatile POA. The suffix "FF" in the case names refers to cases with semivolatile POA and with fragmentation and functionalization treatments, and the suffix "EM3" in the case names refers to cases with 3 times the original NEI POA emissions to take into account for missing SVOC and IVOC species. "n/a" indicates not applicable.

plemented in WRF/Chem in this case is the uncondensed and expanded version $\mathrm{C}$, which includes reactions for peroxy radical operators (Carter, 2010). Species in both CB6MADE/VBS and SAPRC07-MADE/VBS undergo dry deposition, aqueous chemistry, photolysis, and wet scavenging that are similar to CB05-MADE/VBS.

\subsection{Aerosol activation}

The FN05 series aerosol activation parameterizations (with the exclusion of MN14) have been incorporated into 3-D regional air quality models and global climate and Earth system models such as the WRF Community Atmosphere Model version 5 (WRF-CAM5) (Zhang et al., 2015), and in the global-through-urban WRF/Chem (GU-WRF/Chem) (Zhang et al., 2012) and CESM (Gantt et al., 2014). In this study, the FN series parameterizations are incorporated into WRF/Chem following the methods of Gantt et al. (2014) and Zhang et al. (2015), as described in detail in Zhang et al. (2015). However, in WRF/Chem, the aerosol activation module is only linked to the microphysics module through the variable CDNC, which is read by the microphysics module. It is not coupled to the cumulus parameterization scheme unlike in WRF-CAM5 and CESM. The FN05 series has been incorporated into module_mixactivate.F in the physics directory in WRF/Chem. As BN07 involves the entrainment effect for convective clouds and has very small impacts on nonconvective CDNC (Zhang et al., 2015), it is not included in this study. In addition, unlike Gantt et al. (2014) and Zhang et al. (2015), the KU09 treatment is also not included in this study because the empirical constants $A_{\mathrm{FHH}}$ and $B_{\mathrm{FHH}}$ used in the formulation, which are compound-specific, have not been experimentally determined for black carbon, although those constants have been determined for dust and confirmed by Laaksonen et al. (2016). The additional MN14 treatment incorporated in this study involves a small modification to the original FN05 series parameterizations (without KU09), and helps to better account for the size of inertially limited $\mathrm{CCN}$, and to remove a discontinuity in the calculation of the surface area of cloud droplets (Morales Betancourt and Nenes, 2014). The updated treatments are about $20 \%$ more computationally expensive to run compared to ARG00 (Zhang et al., 2015), but capture the sensitivity of CDNC to all aspects of the aerosol with comparable accuracy to numerical parcel models, which was shown to be an underlying reason for biases from ARG (Morales Betancourt and Nenes, 2014).

\section{Results and discussions}

\subsection{Sensitivity simulations with VBS treatments coupled with $\mathrm{CBO5}$}

As listed in Table 4, a number of sensitivity simulations are designed to identify the best model configuration for OA treatments with the closest agreement to observations over CONUS. Those sensitivity simulations consider (i) two SOA modules (MADE/SORGAM versus MADE/VBS), (ii) two types of VBS treatment for POA (nonvolatile POA versus semivolatile POA), (iii) two $H_{\text {vap }}$ treatments (default 
Table 5. Range of statistics for OA / OC ratios of 1.4 and 2.1 (1.4/2.1) for May to June 2010. All simulations use the ARG00 aerosol activation scheme and the Grell-Freitas cumulus parameterization.

\begin{tabular}{|c|c|c|c|c|c|}
\hline Case & Mean Obs & Mean Sim & Corr & $\operatorname{NMB}(\%)$ & NME $(\%)$ \\
\hline \multicolumn{6}{|c|}{ OC against IMPROVE } \\
\hline CB05-SORG-DH & 0.88 & $0.28 / 0.19$ & 0.26 & $-68.1 /-78.7$ & $73.9 / 80.9$ \\
\hline CB05-VBS-DH & 0.88 & $1.19 / 0.79$ & 0.51 & $34.9 /-10.1$ & $75.5 / 52.3$ \\
\hline CB05-POA-DH & 0.88 & $0.89 / 0.59$ & 0.51 & $1.1 /-32.6$ & $52.4 / 59.0$ \\
\hline CB05-POA & 0.88 & $1.05 / 0.70$ & 0.51 & $18.9 /-20.7$ & $63.2 / 49.2$ \\
\hline CB05-10\%FF & 0.88 & $1.05 / 0.70$ & 0.51 & $19.4 /-20.4$ & $63.0 / 49.1$ \\
\hline $\mathrm{CB} 05-25 \% \mathrm{FF}$ & 0.88 & $0.86 / 0.57$ & 0.49 & $-2.9 /-35.2$ & $54.6 / 51.4$ \\
\hline CB05-50\%FF & 0.88 & $0.56 / 0.37$ & 0.45 & $-36.4 /-57.6$ & $54.4 / 62.6$ \\
\hline CB05-25\%FF-EM3 & 0.88 & $1.09 / 0.73$ & 0.47 & $23.8 /-17.5$ & $65.9 / 50.2$ \\
\hline CB6-25\%FF-EM3 & 0.88 & $1.06 / 0.71$ & 0.48 & $20.5 /-19.6$ & $49.4 / 63.7$ \\
\hline SAPRC07-25\%FF-EM3 & 0.88 & $1.00 / 0.67$ & 0.46 & $13.3 /-24.4$ & $60.1 / 50.4$ \\
\hline \multicolumn{6}{|c|}{ TC against IMPROVE } \\
\hline CB05-SORG-DH & 1.03 & $0.44 / 0.34$ & 0.30 & $-57.6 /-66.7$ & $67.9 / 72.3$ \\
\hline CB05-VBS-DH & 1.03 & $1.34 / 0.94$ & 0.52 & $30.6 /-8.0$ & $70.3 / 51.1$ \\
\hline CB05-POA-DH & 1.03 & $1.13 / 0.83$ & 0.52 & $10.2 /-18.7$ & $58.5 / 48.7$ \\
\hline CB05-POA & 1.03 & $1.29 / 0.94$ & 0.53 & $25.6 /-8.5$ & $63.8 / 48.3$ \\
\hline CB05-10\%FF & 1.03 & $1.29 / 0.94$ & 0.53 & $25.9 /-8.2$ & $63.8 / 48.2$ \\
\hline $\mathrm{CB} 05-25 \% \mathrm{FF}$ & 1.03 & $1.09 / 0.83$ & 0.51 & $6.8 /-21.6$ & $55.2 / 48.2$ \\
\hline $\mathrm{CB} 05-50 \% \mathrm{FF}$ & 1.03 & $0.80 / 0.61$ & 0.47 & $-22.0 /-40.2$ & $50.8 / 53.4$ \\
\hline CB05-25\%FF-EM3 & 1.03 & $1.32 / 0.97$ & 0.49 & $29.7 /-5.7$ & $50.7 / 66.9$ \\
\hline CB6-25\%FF-EM3 & 1.03 & $1.30 / 0.95$ & 0.50 & $27.2 /-7.3$ & $65.2 / 50.0$ \\
\hline SAPRC07-25\%FF-EM3 & 1.03 & $1.23 / 0.90$ & 0.48 & $20.6 /-11.9$ & $61.4 / 49.4$ \\
\hline \multicolumn{6}{|c|}{ TC against STN } \\
\hline CB05-SORG-DH & 2.71 & $1.34 / 1.10$ & 0.29 & $-50.6 /-59.4$ & $60.1 / 64.9$ \\
\hline CB05-VBS-DH & 2.71 & $3.35 / 2.44$ & 0.47 & $23.7 /-5.8$ & $53.1 / 42.0$ \\
\hline CB05-POA-DH & 2.71 & $2.88 / 2.19$ & 0.47 & $6.2 /-19.0$ & $45.5 / 41.6$ \\
\hline CB05-POA & 2.71 & $3.03 / 2.30$ & 0.46 & $11.7 /-15.3$ & $44.6 / 39.9$ \\
\hline $\mathrm{CB} 05-10 \% \mathrm{FF}$ & 2.71 & $3.03 / 2.30$ & 0.46 & $11.8 /-15.3$ & $44.5 / 39.8$ \\
\hline $\mathrm{CB} 05-25 \%-\mathrm{FF}$ & 2.71 & $2.66 / 2.05$ & 0.44 & $-1.8 /-24.3$ & $41.5 / 42.0$ \\
\hline $\mathrm{CB} 05-50 \%-\mathrm{FF}$ & 2.71 & $2.07 / 1.65$ & 0.39 & $-3.8 /-39.1$ & $43.9 / 49.4$ \\
\hline CB05-25\%FF-EM3 & 2.71 & $3.27 / 2.45$ & 0.41 & $20.5 /-9.5$ & $49.7 / 41.7$ \\
\hline CB6-25\%FF-EM3 & 2.71 & $3.39 / 2.45$ & 0.34 & $24.9 /-6.4$ & $54.8 / 45.5$ \\
\hline SAPRC07-25\%FF-EM3 & 2.71 & $3.00 / 2.28$ & 0.41 & $10.7 /-16.1$ & $45.2 / 42.0$ \\
\hline
\end{tabular}

versus the semi-empirical $H_{\text {vap }}$ equation by Epstein et al., 2010), (iv) three different percentages of FF (10, 25, and $50 \%$ ), (v) three sets of POA emissions (default versus 1.5 or 3 times the original NEI POA emissions), (vi) three different gas-phase mechanisms (CB05, CB6, and SAPRC07), and (vii) two different aerosol activation schemes (ARG00 versus combinations of different aerosol activation schemes of the FN05 series: FN05, FN05/BA10, and MN14) All simulations except for CB05-SORG-DH contain the VBS treatments for OA. CB05-SORG-DH and CB05-VBS-DH treat POA emissions as nonvolatile. In addition, the impact of two different cumulus parameterization schemes: Grell-Freitas (Grell and Freitas, 2014) and the MSKF (Zheng et al., 2016) scheme were also tested.
Table 5 summarizes the main statistics for all sensitivity simulations in terms of mean obs, mean sim, Corr, $\mathrm{NMB}$, and NME for hourly $\mathrm{OC}$ and TC concentrations against IMPROVE and hourly TC concentrations against STN, respectively, over the whole CONUS domain. Figure 1 compares the domain-mean hourly averaged observed OC or TC concentrations based on IMPROVE and STN with simulated concentrations calculated based on the ratios of OA / OC of 1.4 and 2.1 for each sensitivity simulation. The domain-mean hourly averaged obs OC concentration is $0.88 \mu \mathrm{g} \mathrm{m}^{-3}$ for IMPROVE, and the domain-mean hourly averaged obs TC concentration is $1.03 \mu \mathrm{g} \mathrm{m}^{-3}$ for IMPROVE and $2.71 \mu \mathrm{g} \mathrm{m}^{-3}$ for STN. As shown in Fig. 1, the simulation CB05_SORG_DH with the default SOA module SORG largely underpredicts $\mathrm{OC}$ and TC with the largest NMBs and 

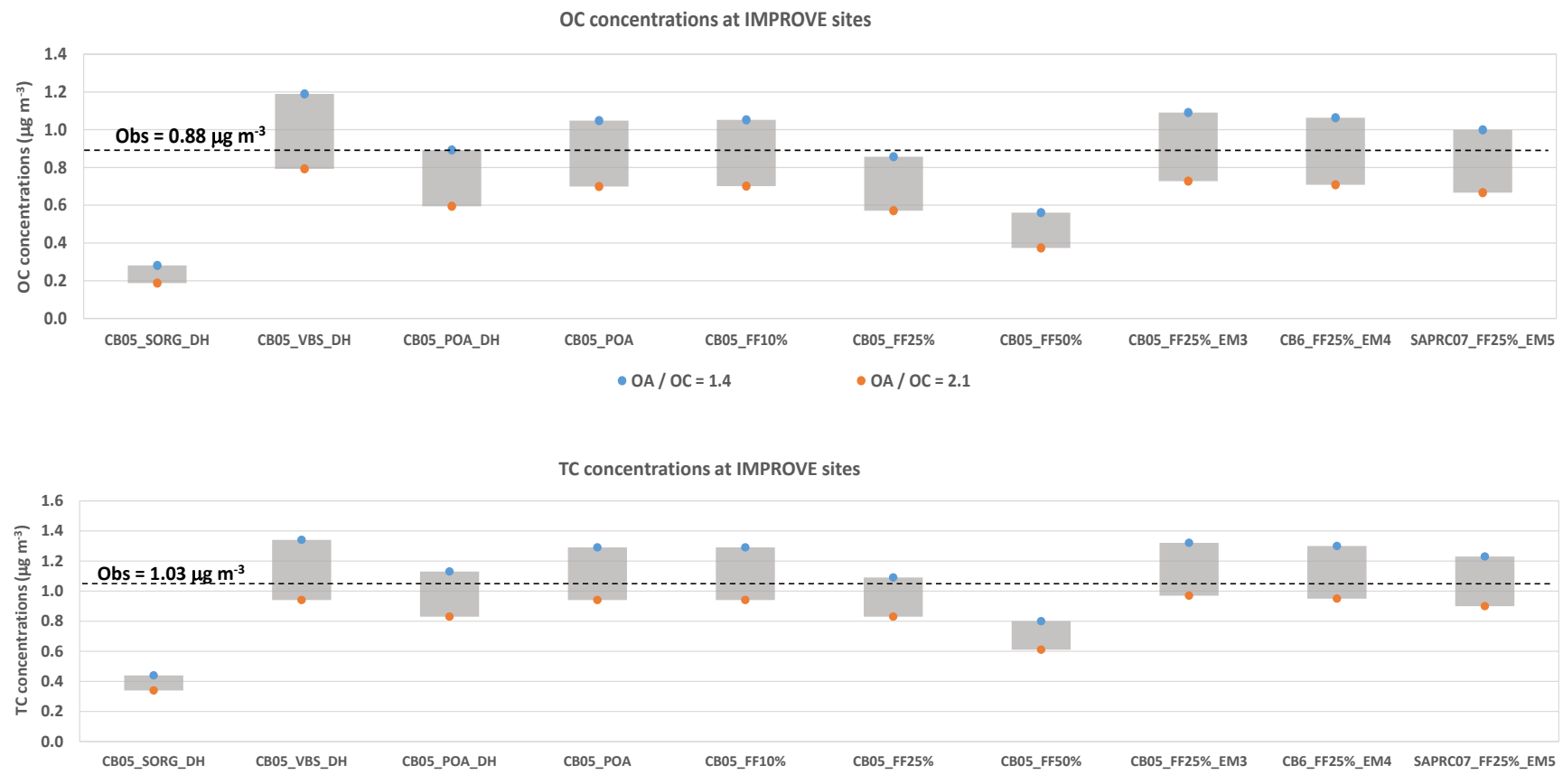
$\bullet \mathrm{OA} / \mathrm{OC}=1.4 \quad-\mathrm{OA} / \mathrm{OC}=2.1$

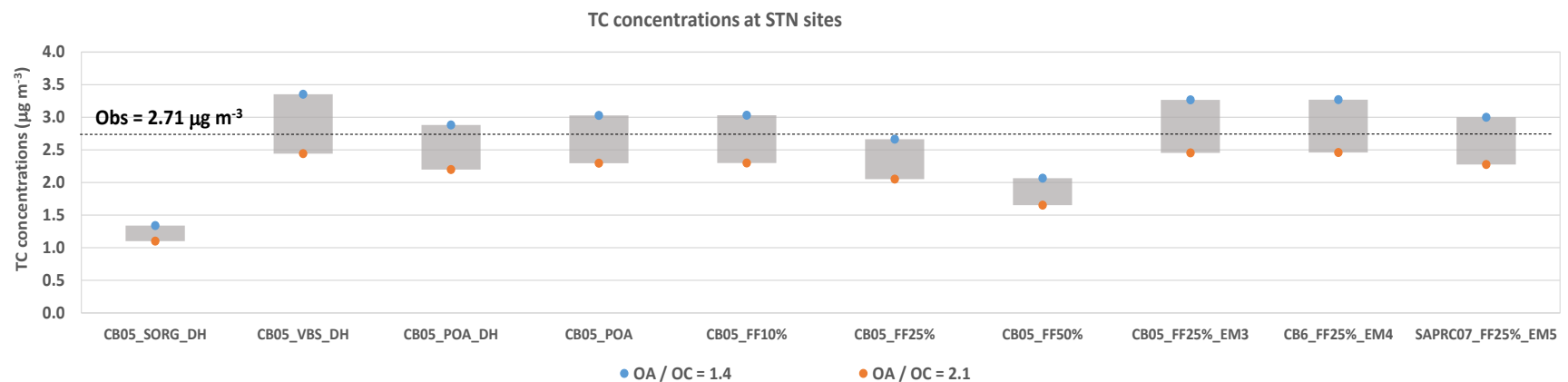

Figure 1. Sim OC and TC concentrations against observations from IMPROVE and STN under two OA / OC ratios, 1.4 and 2.1, resulting in a range of possible OC or TC values denoted by the gray bars. The obs OC or TC is denoted by the horizontal dotted line.

NMEs and the lowest Corr compared to all other simulations with a SOA module based on the VBS method. The remaining VBS simulations significantly reduce the biases and errors in OC and TC from CB05_SORG_DH and also improve the correlation. Compared to CB05_SORG_DH, CB05_VBS_DH with nonvolatile POA seems to perform relatively well in terms of NMBs and Corr against IMPROVE OC, IMPROVE TC, and STN TC.

Adding the semivolatile POA treatment with 1.5 times the NEI POA emissions (CB05_POA_DH) reduces simulated OC and TC concentrations compared to CB05_VBS_DH, due to the loss of mass from the semivolatile POA. As the POA mass is reduced, less surface area is available for SOA precursors to condense onto, resulting in decreased OA (and thus decreased OC and TC) for CB05_POA_DH. Using the semi-empirical correlation of Epstein et al. (2010) for $H_{\text {vap }}$ increases the OC and TC concentrations (CB05_POA versus CB05_POA_DH). Compared to the default $H_{\text {vap }}$ of $30 \mathrm{~kJ} \mathrm{~mol}^{-1}$ used in CB05_POA_DH, the semi-empirical correlation of Epstein et al. (2010) gives much higher $H_{\text {vap }}$ values, resulting in more of the organic vapors in the particulate phase than in the gas phase. Compared to CB05-POA, the simulations with various FF treatments decrease the OA concentrations, as part of the OA mass is fragmented to higher volatility bins. The $10 \% \mathrm{FF}$ case (CB05_10\%FF) does not differ significantly from the case with no FF (CB05_POA). However, increasing the percentage of FF (from 10 to $25 \%$, then to $50 \%$ ) decreases the OA concentrations. The FF treatments, however, even if they are more representative of actual SOA atmospheric formation 

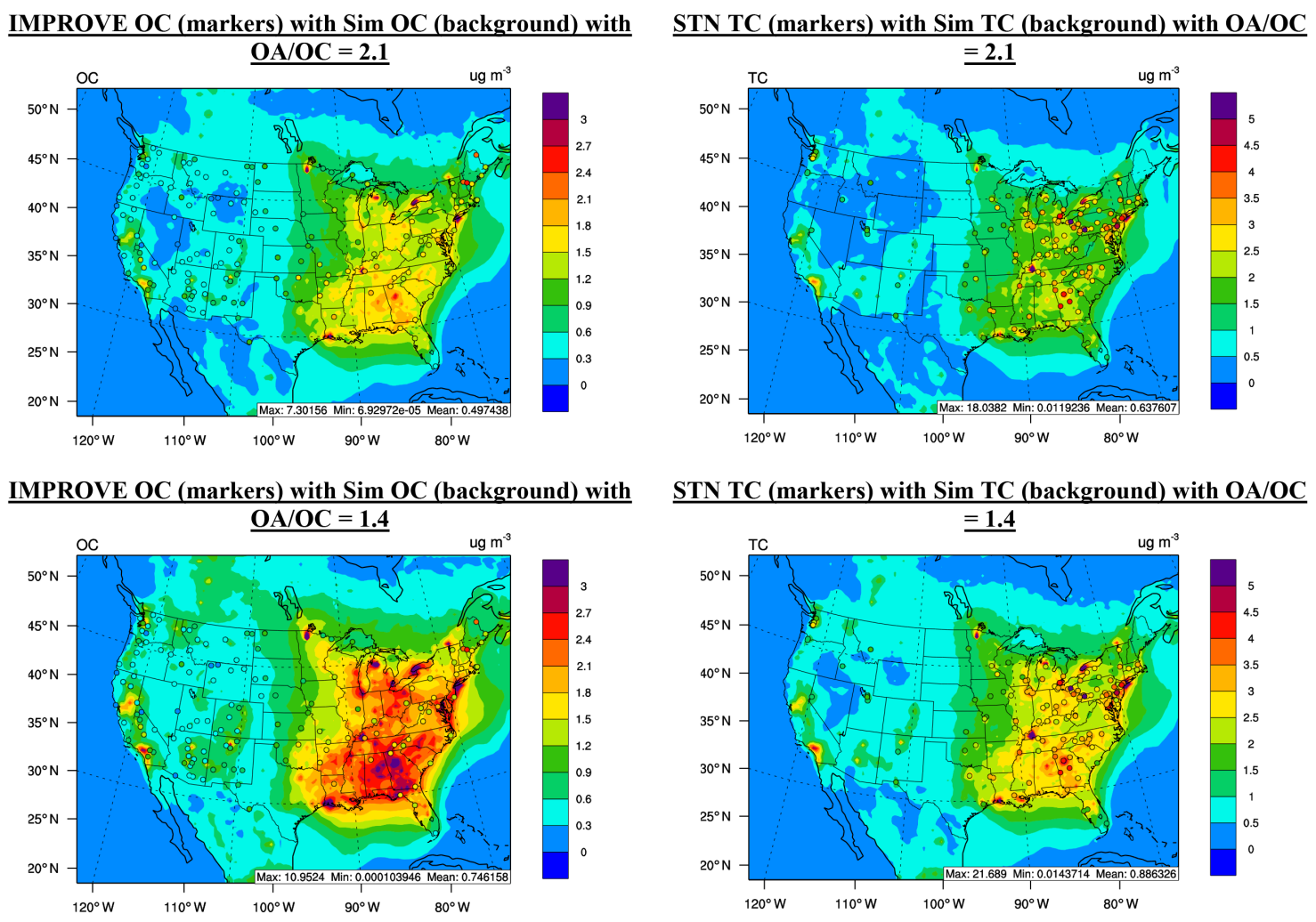

Figure 2. Overlay of obs data (markers) vs. sim data (background) for IMPROVE OC and STN TC and for OA / OC ratios of 1.4 and 2.1 for the case CB05_25\%FF_EM3.

processes, reduce the Corr slightly (compared to the cases CB05_POA and CB05-10\%FF). By doubling the POA emissions (from 1.5 to 3.0 times the original POA NEI emissions) for the $25 \% \mathrm{FF}$ case (CB05_FF25\%_EM3), the predicted $\mathrm{OC}$ and TC concentrations are closer to the observations. When evaluated against IMPROVE OC, IMPROVE TC, and STN TC, among simulations using CB05, the simulations CB05_VBS_DH, CB05_POA, CB05_FF10\%, and CB05_FF25\%_EM3 perform better than other cases. The differences in the OC and TC predictions from the simulations with different gas-phase mechanisms will be discussed later in Sect. 2.

Figure 2 shows the spatial distributions of simulated OC and TC concentrations overlaid with observed OC from IMPROVE and TC from STN for the case CB05_25\%FF_EM3 for the two OA / OC ratios. The model performs much better for IMPROVE OC with an OA / OC ratio of $2.1 \mathrm{com}-$ pared to 1.4 , especially over the eastern US, where the use of an OA / OC ratio of 1.4 results in large overpredictions. On the one hand, over the central US and parts of the western US, the use of an OA/OC ratio of 1.4 shows slightly better predictions of IMPROVE OC compared to the use of OA / OC ratio of 2.1 that gives underpredictions of OC. On the other hand, the model performs better for STN OC with an OA / OC ratio of 1.4 compared to 2.1. The use of an
OA / OC ratio of 1.4 gives better agreement with STN TC over the eastern US where the use of an OA / OC ratio of 2.1 results in large underpredictions of TC. Evaluation of OC and TC against IMPROVE and STN, respectively, therefore depends heavily on the OA / OC ratio, which is site-specific. Therefore in more rural sites (IMPROVE), the OA / OC ratio is more likely to be high $(\sim 2.1)$ with more oxygenated OA, while in more urban sites (STN), the OA / OC ratio is more likely to be lower $(\sim 1.4)$ due to fresher emissions and less oxidized species.

Figure 3 shows the POA/OA ratios for six sensitivity simulations. As mentioned earlier, the observed ratio of $\mathrm{POA}$ / total OA is approximately 15 to $40 \%$ during the summer period over various locations in the CONUS. As SOA concentrations from field campaigns are sparse at different locations and at different time periods, the POA / OA ratio is used to evaluate the model's capability to reproduce POA and SOA concentrations. The simulation CB05_SORG_DH, with the default SORGAM SOA module, largely overpredicts the POA / OA ratio, due to significant underpredictions of SOA. The simulations CB05_VBS_DH, CB05_50\%FF, and CB05_25\%FF_EM3, with various VBS treatments, all have POA/OA ratios that fall within the range of 0.15 to 0.4 , with lower POA / OA ratios over more rural areas and higher POA / OA ratios over urban areas. CB05_VBS_DH, 

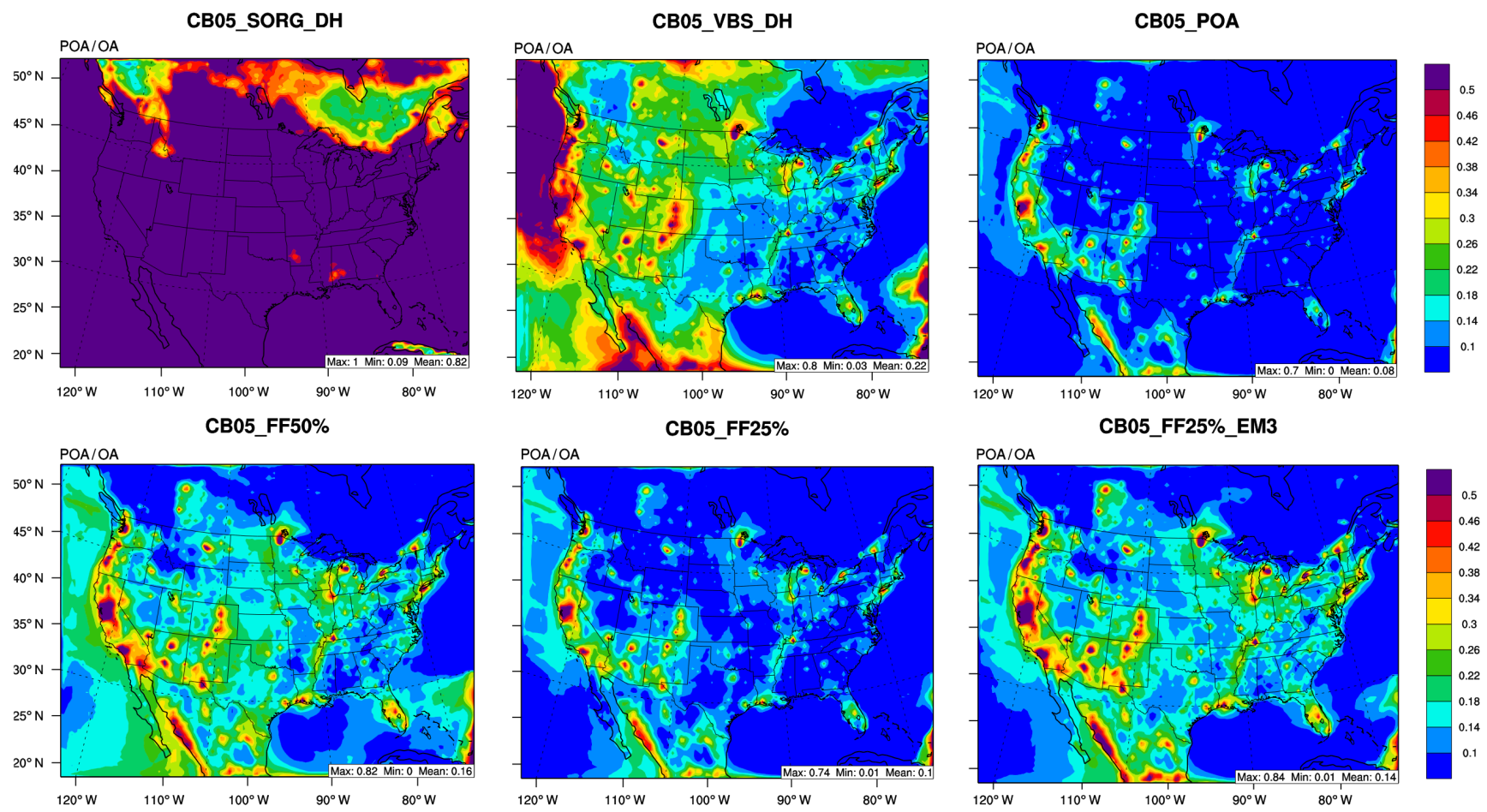

Figure 3. POA / OA ratios of sim data from various sensitivity simulation cases.

however, might give too-high POA concentrations over the western portion of the domain as it does not consider POA to be semivolatile. Considering semivolatile POA, however, without considering the fragmentation and functionalization processes in the simulation CB05_POA results in too-low POA / OA ratio ( $<0.1$ over most areas). Similarly, the CB05_FF25\% case also results in a large portion of CONUS having POA / OA ratios of $<0.1$, due to the loss of POA mass. CB05_FF50\%, however, predicts reasonable POA / OA ratios, even with FF due to balanced loss of both POA and SOA mass through fragmentation to higher volatility bins. The simulation CB05_FF25\%_EM3 also improves from CB05_FF25\% by increasing the POA mass contributing to higher POA / OA ratios.

Figure 4 shows the observed and simulated temporal variations of SOA concentrations at the two CalNex sites, Bakersfield and Pasadena in CA, from May to June 2010 for the simulations CB05_SORM_DH, CB05_VBS_DH, CB05_25\%FF_EM3, CB6_25\%FF_EM3, and SAPRC07_25\%FF_EM3. There are large underpredictions of SOA by all runs on some days (e.g., 15-16 May, 2-6 June, 13-14 June), likely due to missing SOA precursor emissions. Table 6 shows the statistics of the simulations presented in Fig. 4. The results using CB6 and SAPRC07 gas-phase mechanisms will be discussed in Sect. 4.2. The observed SOA was derived based on the tracer method of Kleindienst et al. (2012) which contains some uncertainties, and also likely contributes to the poor correlation for most of the cases. For example, it assumes mass fraction of the tracers in secondary organic carbon is the same in the field as that in the laboratory, and the tracers are assumed to be inert and are unlikely to undergo oxidation in the atmosphere, which might not be the case. In addition, the SOA data from the CalNex campaign only consider contributions from a small number of precursors including biogenic precursors (i.e., isoprene, $\alpha$-pinene, and $\beta$-caryophyllene), and the anthropogenic precursors (i.e., toluene, polycyclic aromatic hydrocarbons, and methyl butenol).

As shown in Fig. 4 and Table 6, the simulation CB05_SORG_DH with the default SORGAM SOA module significantly underpredicts observed SOA concentrations at both sites. The model configuration of CB05_VBS_DH has been used in a number of WRF/Chem simulations published in the literature (e.g., Yahya et al., 2016; Campbell et al., 2015; Wang et al., 2015). At Bakersfield, the simulation CB05_VBS_DH overpredicts the SOA concentrations for almost all the days. The simulation CB05_25\%FF_EM3, however, underpredicts the SOA concentrations at Bakersfield, especially in June. The CB05_25\%FF_EM3 case also shows low SOA concentrations throughout May and June, without much variability in SOA concentrations, likely due to underestimations of original POA emissions at Bakersfield. As the SVOC and IVOC emissions for CB05_25\%FF_EM3 are a factor of 3 of the original POA emissions from NEI, if the original POA emissions from NEI are underestimated, the SVOC and IVOC emissions will be low, resulting in 
Table 6. Statistics for evaluation at Bakersfield and Pasadena sites. A bar chart of daily average obs vs. sim values can be found in Fig. 4.

\begin{tabular}{lcrrrr}
\hline Case & Mean Obs & Mean Sim & Corr & NMB (\%) & NME (\%) \\
\hline \multicolumn{5}{c}{ Bakersfield } \\
\hline CB05-SORG-DH & 0.51 & $5.9 \times 10^{-4}$ & -0.15 & -100 & $100 \%$ \\
CB05-VBS-DH & 0.51 & 0.67 & 0.41 & 32.5 & 62.0 \\
CB05-25\%FF-EM3 & 0.51 & 0.24 & -0.01 & -52.0 & 61.0 \\
CB6-25\%FF-EM3 & 0.51 & 0.28 & -0.04 & -45.8 & 59.0 \\
SAPRC07-25\%FF-EM3 & 0.51 & 0.24 & -0.16 & -53.1 & 63.0 \\
\hline \multicolumn{7}{c}{ Pasadena } \\
\hline CB05-SORG-DH & 0.63 & 0.04 & -0.07 & -94.0 & 94.0 \\
CB05-VBS-DH & 0.63 & 0.54 & 0.09 & -14.5 & 64.3 \\
CB05-25\%FF-EM3 & 0.63 & 0.54 & -0.2 & -14.4 & 66.2 \\
CB6-25\%FF-EM3 & 0.63 & 0.62 & -0.2 & -2.1 & 70.0 \\
SAPRC07-25\%FF-EM3 & 0.63 & 0.62 & 0.03 & -1.4 & 70.5 \\
\hline
\end{tabular}
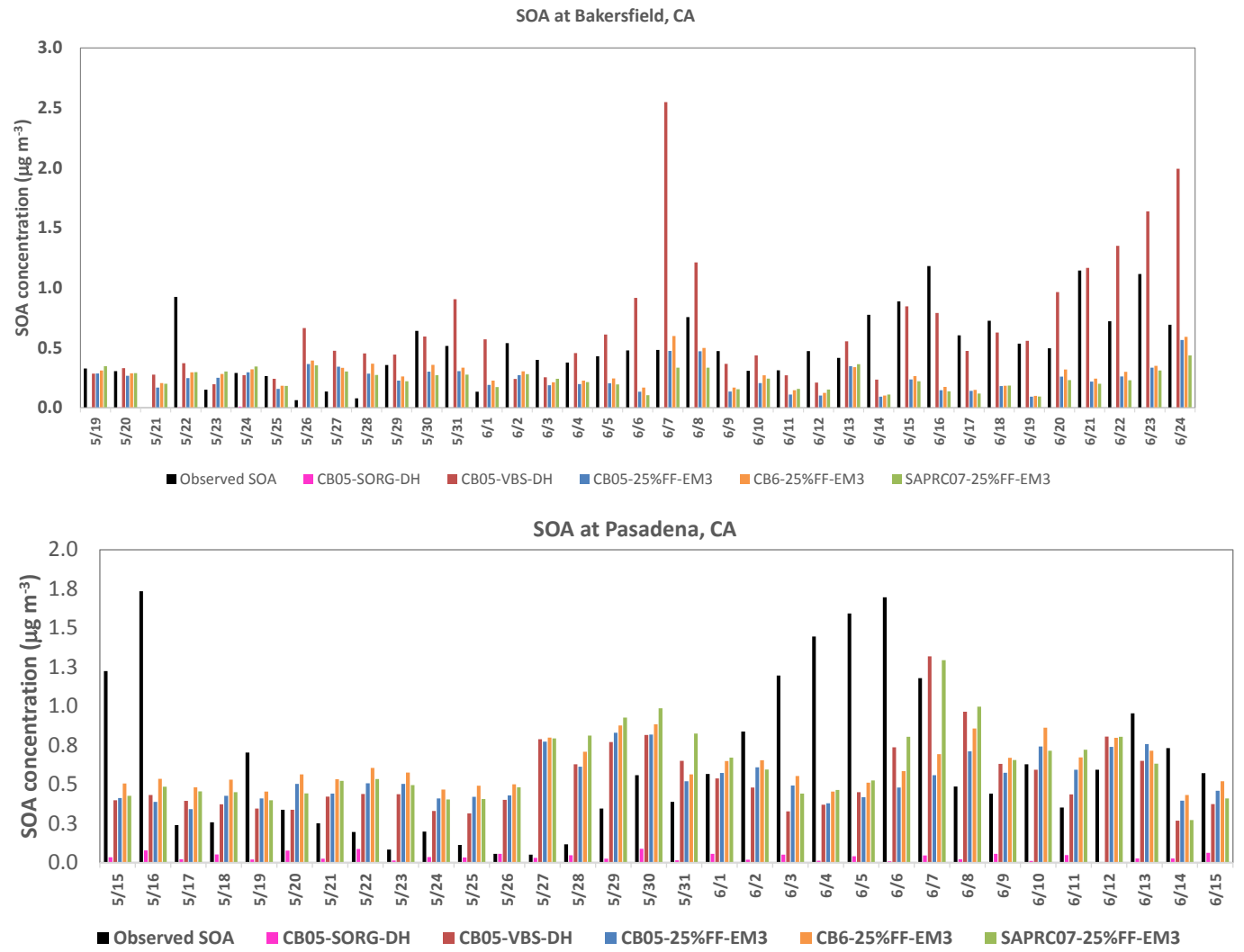

Figure 4. Comparison of obs SOA vs. sim SOA at CalNex sites in Bakersfield and Pasadena in California.

low SOA concentrations due to low concentrations of condensable material. At Pasadena, both CB05_VBS_DH and CB05_25\%FF_EM3 overpredict the obs SOA from 15 to 30 May, but are unable to capture the high SOA concentrations from 2 to 6 June. The CB05_VBS_DH case seems to perform better than the CB05_25\%FF_EM3 case when observed SOA concentrations are high. The results from this study are consistent with those from Baker et al. (2015), which showed that measured $\mathrm{PM}_{2.5}$ OC at Bakersfield is largely underpredicted compared to Pasadena. Baker et al. (2015), however, attributed to the underpredictions of $\mathrm{OC}$ at Bakersfield and Pasadena mainly to primary OC predicted by the baseline model, compared to the aerosol mass spectrometer measurements, suggesting that OC is mostly secondary in nature in Pasadena. In addition, as mentioned earlier, the simulated SOA from WRF/Chem 
does not consider contributions from all the SOA precursors identified by their trace compounds (e.g., the biogenic precursor, b-caryophyllene, and the anthropogenic precursor methyl butenol, are not included in WRF/Chem), which can help to account for the discrepancies between the simulated and observed SOA concentrations.

\subsection{Sensitivity of OA predictions to different gas-phase mechanisms}

Figure 1 shows that CB05_FF25\%_EM3 produces the highest OC and TC concentrations at the IMPROVE sites, followed by CB6_FF25\%_EM3 and SAPRC07_FF25\%_EM3, while CB6_FF25\%_EM3 produces the highest TC concentrations at the STN sites. However, the differences in domainmean simulated OC and TC between the simulations with the three different gas-phase mechanisms are small compared to the differences in simulated $\mathrm{OC}$ and TC due to differences in VBS treatments (e.g., nonvolatile versus semivolatile POA). Figure 4 also shows that there are not many differences between simulated SOA concentrations with different gasphase mechanisms at Bakersfield, but larger differences are found at Pasadena. For example, SAPRC07_25\%FF_EM3 produces much higher SOA concentrations compared to CB05_25\%FF_EM3 and CB6_25\%FF_EM3 at Pasadena on several days (e.g., 6-8 June). Figure 5 shows the time series of hydroxyl radical mixing ratios as well as diurnal plots of $\mathrm{OH}$ and hydroperoxyl radical at Pasadena from the CalNex field campaign. The time series of $\mathrm{HO}_{2}$ is not shown due to irregularity of the observational data. The model is able to reproduce the diurnal variation of $\mathrm{OH}$ radicals but significantly overpredicts the daytime and peak $\mathrm{OH}$ mixing ratios, especially for CB05 and CB6. All gas-phase mechanisms underpredict $\mathrm{OH}$ mixing ratios at night. Among all simulations, SAPRC07 produces the closest simulated $\mathrm{OH}$ mixing ratios compared to $\mathrm{CB} 05$, and CB6 gives the largest overpredictions. Similarly, the $\mathrm{HO}_{2}$ mixing ratios are generally overpredicted by all gas-phase mechanisms with SAPRC07 performing the best. The overpredictions in $\mathrm{OH}$ and $\mathrm{HO}_{2}$ mixing ratios do not help explain the underpredictions of SOA for several days at Pasadena where underpredictions of VOCs may be the main cause, which is consistent with the findings of Baker et al. (2015).

Figure 6 shows spatial distributions of average concentrations of oxidants including ozone $\left(\mathrm{O}_{3}\right), \mathrm{OH}$, and $\mathrm{HO}_{2}$, as well as the OA species including anthropogenic SOA (ASOA), biogenic SOA (BSOA), total SOA, and POA. SAPRC07$25 \%$ FF-EM3 produces the highest domain-average $\mathrm{O}_{3}$ mixing ratios but the lowest domain-average $\mathrm{OH}+\mathrm{HO}_{2}$ mixing ratios, while CB6-25\%FF-EM3 produces the highest domain-average and maximum $\mathrm{OH}+\mathrm{HO}_{2}$ mixing ratios but the lowest domain-average $\mathrm{O}_{3}$ mixing ratios. These findings are mostly consistent with the literature. For example, maximum $\mathrm{O}_{3}$ and $\mathrm{OH}$ mixing ratios over the Los Angeles area are higher for CB6 compared to CB05, which are consistent with the results from Yarwood et al. (2010). SAPRC07 also generally produces higher $\mathrm{O}_{3}$ mixing ratios compared to $\mathrm{CB} 05$. However, average $\mathrm{O}_{3}$ mixing ratios from $\mathrm{CB} 6$ are expected to be higher than CB05 (rather than lower, as shown in Fig. 6), according to the study from Nopmongcol et al. (2012) which showed higher $\mathrm{O}_{3}$ mixing ratios over Europe for January and July using the Comprehensive Air Quality Model with Extensions (CAMx). CB6 is a relatively new gas-phase mechanism, and there are very few studies that evaluated its performance over a longer period of time (e.g., for the whole summer) and over CONUS. In addition, there are other uncertainties in this study. For example, the emissions for CB05 are used for CB6, the additional explicit VOC species in CB6 such as benzene and acetylene are not considered, which can also contribute to $\mathrm{O}_{3}$ formation. In addition, most locations in the US in 2010 are considered to be $\mathrm{NO}_{x}$-limited with localized VOC-limited regimes from May to September (Campbell et al., 2015), which means that $\mathrm{O}_{3}$ formation is more likely to depend on $\mathrm{NO}_{x}$ rather than VOC concentrations.

Table 7 shows the statistics for maximum $1 \mathrm{~h}$ and $8 \mathrm{~h} \mathrm{O}$ mixing ratios evaluated against CASTNET and AQS. CASTNET sites are mainly rural sites, while AQS consists of urban, suburban, and rural sites. As expected, SAPRC07 consistently produces the highest maximum $1 \mathrm{~h}$ and maximum $8 \mathrm{~h} \mathrm{O}_{3}$ mixing ratios and overpredicts at AQS sites with an NMB of $\sim 16 \%$. However, SAPRC07 performs the best at CASTNET sites, as both CB05 and CB6 significantly underpredict maximum $1 \mathrm{~h}$ and maximum $8 \mathrm{~h} \mathrm{O}_{3}$ mixing ratios. At CASTNET sites, CB6 performs the poorest with the largest underpredictions for both maximum $1 \mathrm{~h}$ and $8 \mathrm{~h} \mathrm{O}_{3}$ mixing ratios. However, CB6 predicts higher maximum $1 \mathrm{~h}$ and $8 \mathrm{~h}$ $\mathrm{O}_{3}$ mixing ratios at $\mathrm{AQS}$ sites, while $\mathrm{CB} 05$ predicts the lowest maximum $1 \mathrm{~h}$ and $8 \mathrm{~h} \mathrm{O}_{3}$ mixing ratios at AQS sites. It is likely that $\mathrm{CB} 6$ predicts higher $\mathrm{O}_{3}$ mixing ratios at more VOC-limited sites in urban areas, while $\mathrm{CB} 05$ predicts higher $\mathrm{O}_{3}$ mixing ratios at more $\mathrm{NO}_{x}$-limited areas, due to the improvement in VOC speciation in CB6 compared to CB05. Overall, however, CB05 has the highest Corr and the lowest NMEs for CASTNET maximum $1 \mathrm{~h}$ and AQS maximum $1 \mathrm{~h}$ and $8 \mathrm{~h} \mathrm{O}_{3}$ mixing ratios. For $\mathrm{PM}_{2.5}$ concentrations, $\mathrm{CB} 6$ produces the best performance against IMPROVE (highest Corr, lowest NMB and NME) while CB05 produces the best performance against STN (highest Corr and lowest NME). All three cases perform poorly for PM10 against AQS, with large underpredictions due to the lack of consideration of the coarse-mode inorganic species in MADE-VBS treatments.

ASOA concentrations are lower for CB6 and SAPRC07 compared to CB05. This is likely partially due to the emissions which are mapped from CB05 to CB6 and SAPRC07. The CB05 emissions are not likely to account for all anthropogenic VOC emissions in CB6 and SAPRC07, resulting in lower ASOA concentrations for CB6 and SAPRC07 compared to CB05. BSOA concentrations, however, are the largest for CB6, followed by SAPRC07 and CB05. BSOA concentrations are likely the highest for CB6 due to the high- 


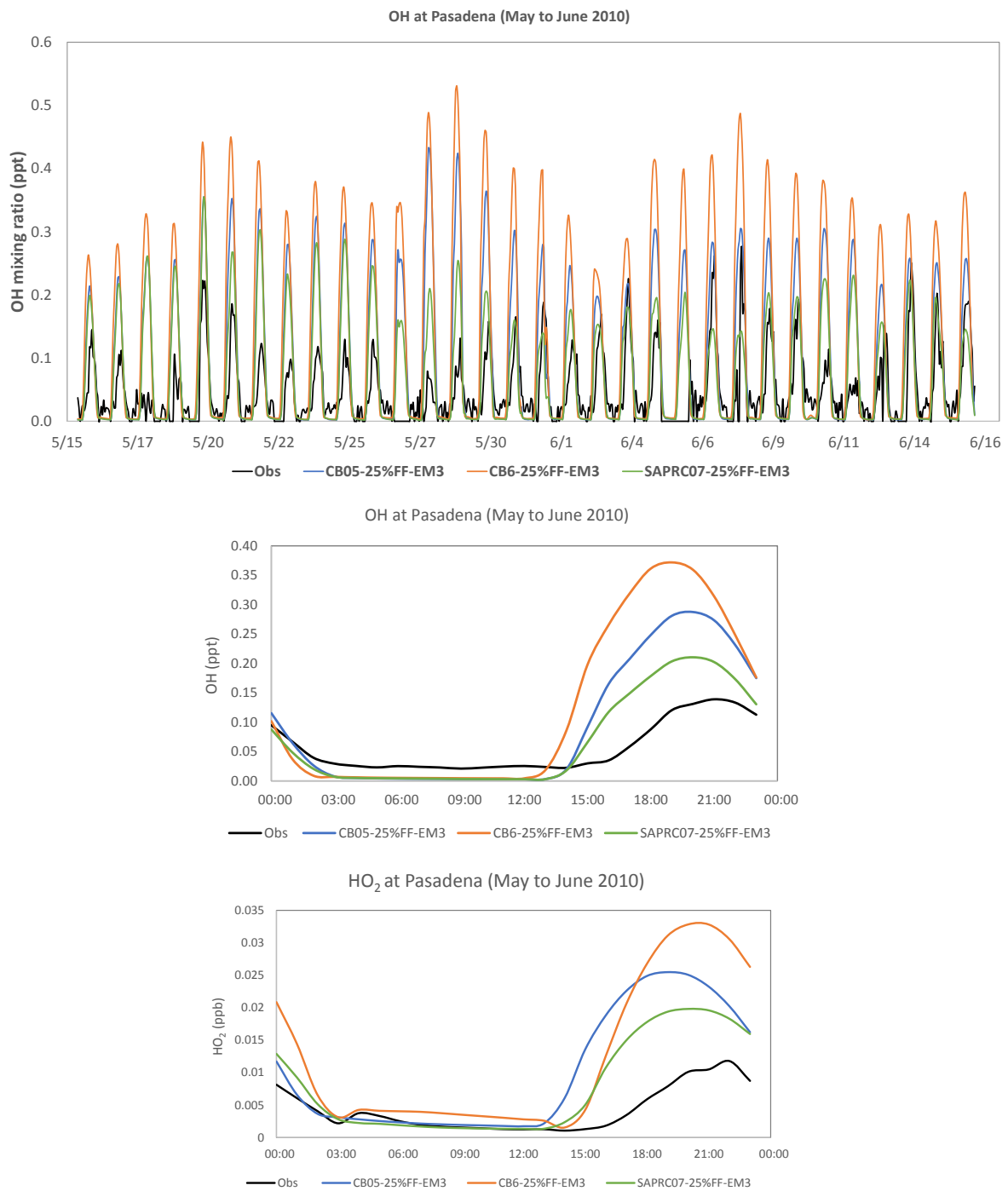

Figure 5. Time series of $\mathrm{OH}$ and diurnal plots of $\mathrm{OH}$ and $\mathrm{HO}_{2}$ at Pasadena, CA, during CALNEX, 2010.

est $\mathrm{OH}+\mathrm{HO}_{2}$ mixing ratios for CB6. The more extensive VOC representation and high $\mathrm{O}_{3}$ mixing ratios for SAPRC07 also likely contribute to the high BSOA concentrations for SAPRC07 compared to CB05. However, overall, the total SOA and POA concentrations for all three gas-phase mechanisms do not vary much, resulting in similar OA concentrations.

Figures 7 and 8 show the time series of simulated versus observed OC from IMPROVE and simulated versus observed TC from STN at several representative sites over CONUS for the different gas-phase mechanisms. In general, at IMPROVE sites, CB05 gives the highest OC concentrations compared to CB6 and SAPRC07 most of the time, resulting in overpredictions of OC concentrations, while CB6 and SAPRC07 perform better against IMPROVE OC. The overpredictions of $\mathrm{CB} 05$ are likely due to overpredictions in ASOA (as CB05 produces the highest ASOA concentrations compared to CB6 and SAPRC07, as shown in Fig. 6). As these sites are located in rural locations, the dominant SOA is likely to be BSOA, or downwind ASOA from more urban areas. With the exception of Death Valley NP, CA, the model performs relatively well in predicting IMPROVE OC concentrations. Simulations with all three gas-phase mechanisms overpredict OC concentrations over several days in May in Brigantine NWR, Death Valley and Swanqwarter, but is able to predict several of the peaks in June. All three gasphase mechanisms, however, largely underpredict OC concentrations over Death Valley from 21 May to 30 June. As the Death Valley NP is a desert, the OC at Death Valley NP is most likely due to downwind OC transported from upwind locations, which the model is not able to capture due to meteorological biases such as biases in wind fields. The differences between simulation results from the gas-phase mechanisms are smaller for STN TC compared to IMPROVE OC, 


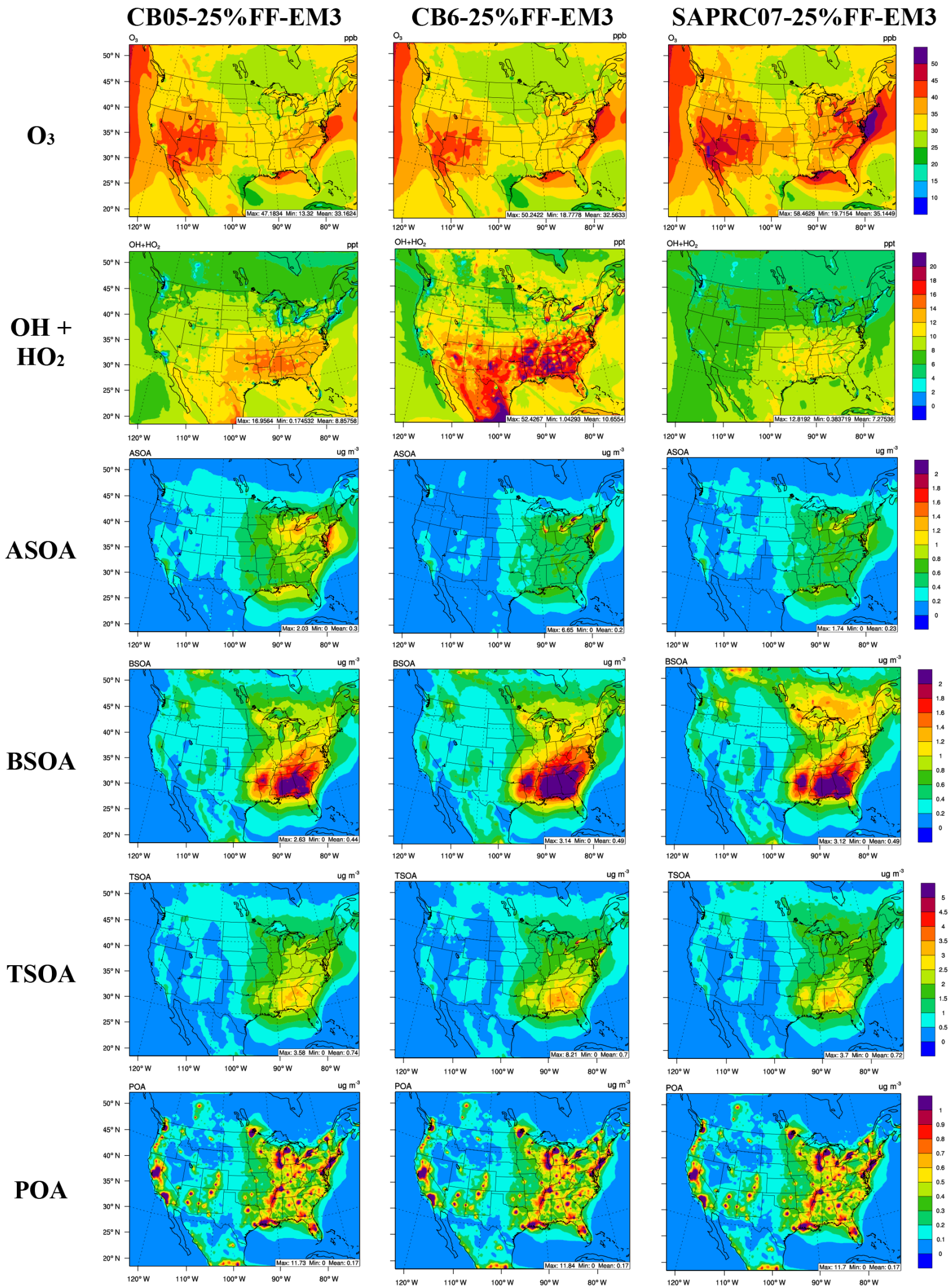

Figure 6. Spatial plots of several gas and aerosol species for the three cases with different gas-phase mechanisms. 

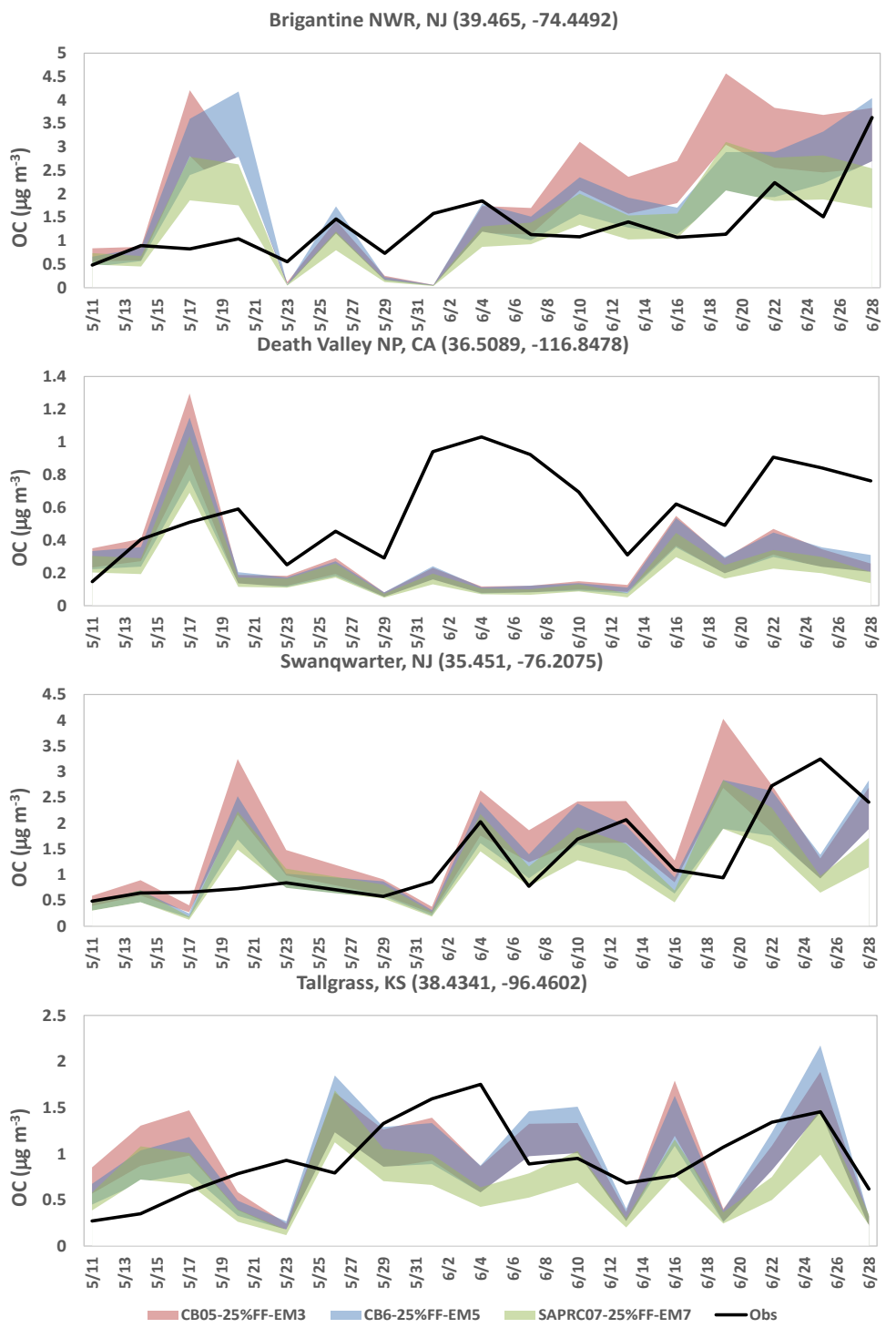

Figure 7. Time-series plots of IMPROVE OC vs. simulated OC at selected sites from sensitivity simulations of different gas-phase mechanisms. The colored bands represent the range of $\mathrm{OC}$ values for ratios 1.4 to 2.1 .

probably due to similar elemental carbon (EC) concentrations for all gas-phase mechanisms, which can form a significant percentage of TC. In general, all simulations with the three gas-phase mechanisms also show similar trends (peaks and troughs) for simulated TC, likely due to influences from meteorological parameters such as wind and precipitation. Overall, all three simulations are also able to predict the magnitude and trends of STN TC concentrations relatively well. Similarly, CB05 tends to produce the highest TC concentrations; however, CB6 does also produce the highest TC concentrations for several days, for example, for some days in May in Washington, DC, and Tampa, FL, as well as in June in Liberty, KS, likely due to influences of BSOA where CB6 produces the highest concentrations, as shown in Fig. 6 .

\subsection{Impact of different VBS treatments on CDNC}

Table 7 shows the statistics for model evaluation for simulated CDNC against MODIS-derived CDNC from Bennartz (2007) for May to June 2010. All simulations underpredict CDNC, likely due to underpredictions in PM and $\mathrm{CCN}$ concentrations and uncertainties and/or assumptions in the derived CDNC based on MODIS retrievals of cloud properties by Bennartz (2007) (Zhang et al., 2015). For example, Bennartz (2007) derived the CDNC from cloud optical depths and cloud effective radius assuming adiabatically stratified clouds. Among all simulations with CB05, CB05_SORG_DH produces the lowest CDNC due to underestimated OA concentrations. Increasing the OA concentrations helps to reduce the negative biases for CDNC. There 


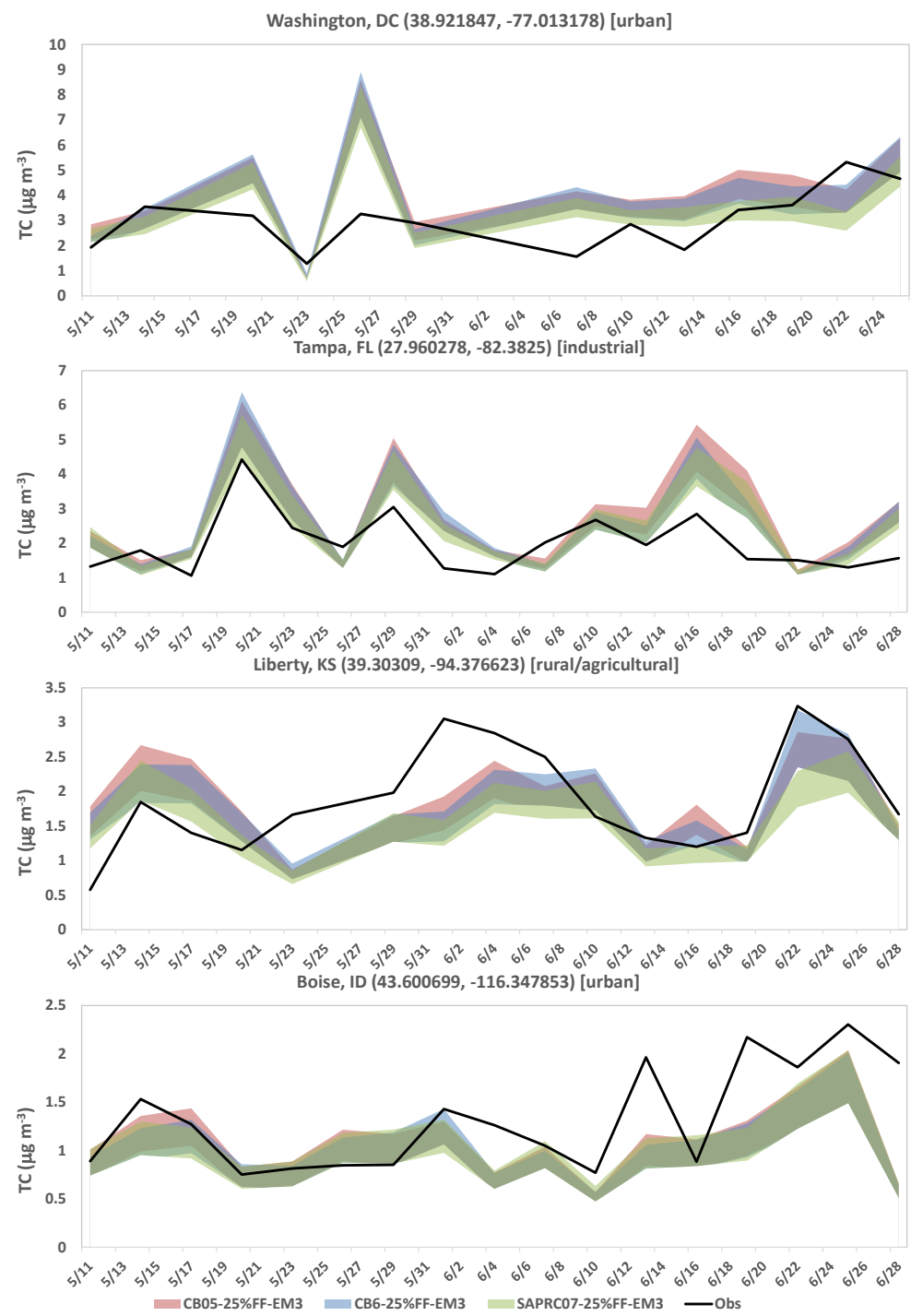

Figure 8. Time-series plots of STN TC vs. simulated TC at selected sites from sensitivity simulations of different gas-phase mechanisms. The colored bands represent the range of OC values for ratios 1.4 to 2.1 .

are small differences, however, among simulated CDNC with different VBS treatments for CB05 in CDNC predictions, with similar Corr $\sim 0.29$, NMBs of $\sim-29$ to $-27 \%$, and NMEs of $\sim 47 \%$. Figure 9 shows the spatial differences in predictions in warm clouds between several simulations and the simulation CB05_VBS_DH. CB05_SORGAM_DH gives the lower CDNC than CB05_VBS_DH, indicating that the VBS treatment in CB05_VBS_DH helps to increase CDNC significantly. While other simulations with semivolatile POA treatments further increase domainaverage CDNC when comparing to CB05_VBS_DH, the differences between CDNC predictions from those simulations and those from CB05_VBS_DH are quite similar. In general, CDNC with the semivolatile POA cases is higher over the western US but lower over the eastern US due to decreases in column OA concentrations for the semivolatile POA cases compared to CB05_VBS_DH over the eastern US.

The large differences in CDNC predictions, however, are found between simulations with the different gas-phase mechanisms. SAPRC07_25\%FF_EM3 has the largest negative bias (NMB of $-52 \%$ ) compared to all other simulations with $\mathrm{CB} 05$ and the simulation with CB6. Figure 10 compares the spatial plots for CDNC predictions for simulations with different gas-phase mechanisms, as well as the surface spatial plots for total OA and inorganic $\mathrm{PM}_{2.5}$ concentrations. The simulation with SAPRC07 shows significantly lower CDNC over the northeastern US compared to CDNC predictions from the other two simulations. While all three simulations show similar total OA concentrations, large differences are found for their total inorganic $\mathrm{PM}_{2.5}$ concen- 

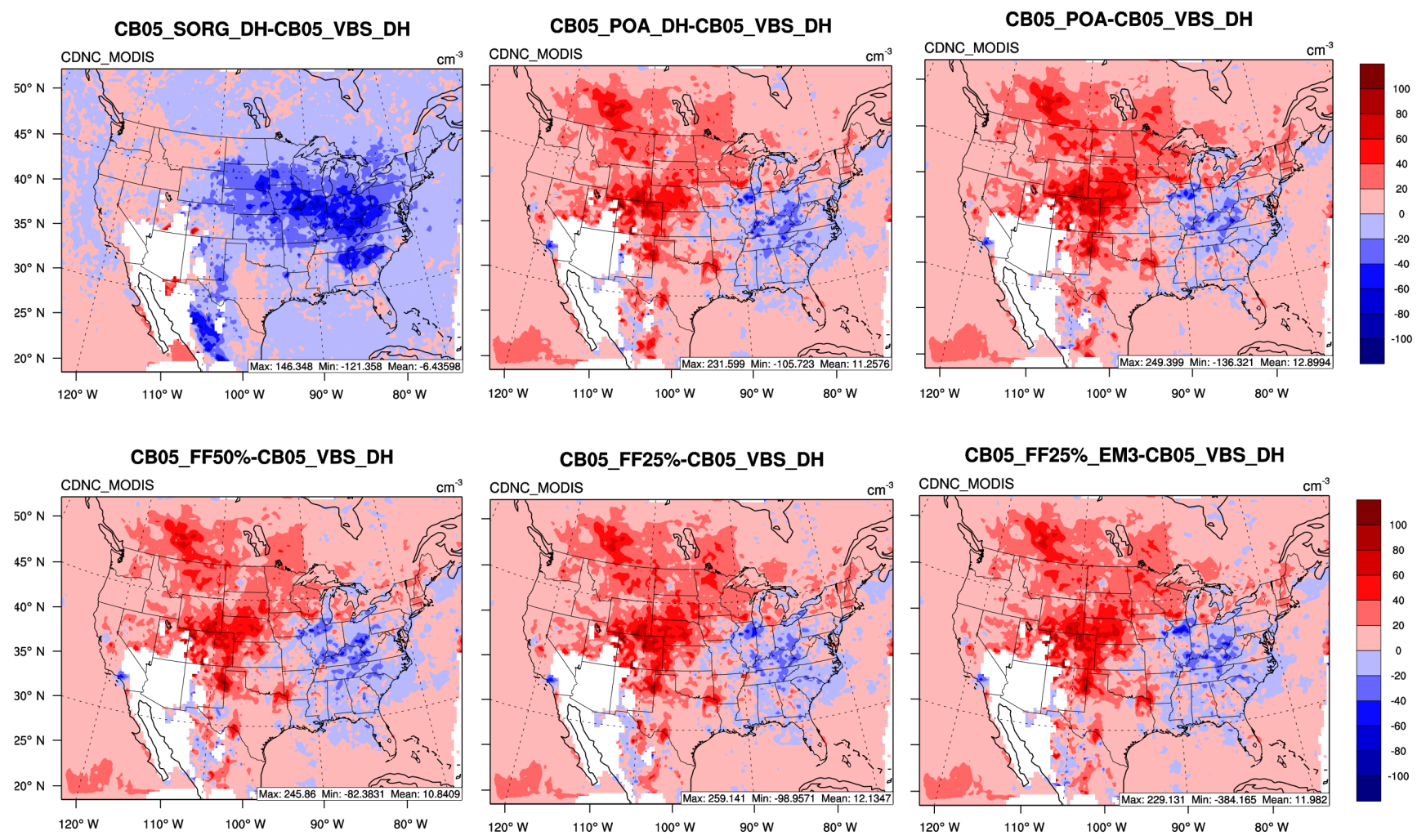

Figure 9. Impact of different VBS cases on CDNC in warm clouds. The plots show the differences between the different sensitivity simulations and CB05_VBS-DH.

trations, with SAPRC07 producing the lowest domain mean and maximum total inorganic $\mathrm{PM}_{2.5}$ concentrations. Compared to CB05 and CB6, the lower inorganic $\mathrm{PM}_{2.5}$ concentrations simulated with SAPRC07 are likely due to the low $\mathrm{OH}+\mathrm{HO}_{2}$ mixing ratios for SAPRC07, as shown in Fig. 6, resulting in a lower PM number concentration and lower $\mathrm{CCN}$, and thus lower CDNC.

\subsection{Sensitivity simulations for aerosol activation parameterizations}

Among all OA sensitivity simulations, the simulation CB0525\%FF-EM3 gives the overall best performance in terms of OC, TC, $\mathrm{O}_{3}, \mathrm{PM}_{2.5}$, and $\mathrm{CDNC}$ evaluation; it is thus selected to test various aerosol activation parameterizations. Four sensitivity simulations, listed in Table 4, are designed to test the FN05 series aerosol activation parameterizations with improved treatments compared to the default ARG00 aerosol activation parameterization. These sensitivity simulations include the default ARG00, the FN05, the combination of FN05 and BA10, and the MN14. These simulations use the MSKF scheme instead of the Morrison microphysics schemes in the previous SOA runs, as the MSKF scheme has a better correlation with MODIS CDNC compared to the Morrison microphysics scheme. Table 8 summarizes the model evaluation results against MODIS-derived
CDNC from Bennartz (2007). The simulation ARG00 underpredicts CDNC with an NMB of $-35 \%$. The FN05 series helps to reduce the underpredictions of CDNC significantly, because they in general give higher activation fractions compared to the ARG00 parameterization under most atmospheric conditions (Ghan et al., 2011). The addition of BA10 to the FN05 takes into account the effects of condensation on giant $\mathrm{CCN}$, which reduces the $\mathrm{CDNC}$ predictions and leads to a negligible underprediction of CDNC (with an NMB of $-0.8 \%$ ) compared to a slight overprediction by the FN05 with an NMB of 7.1\%. MN14, which revises the original population splitting method in FN05 and BA10, slightly increases the CDNC to an NMB of $4.2 \%$ comparing to the FN05/BA10 simulation. The trends in the predictions of FN05, BA10, and MN14 are consistent with the reported bias of $\sim+8,-10$, and $-3 \%$, respectively, by Morales Betancourt and Nenes (2014) against the CDNC concentrations simulated from the cloud parcel model. However, the Corr and NME are worse with the FN05 series and MN14. The NMEs are almost doubled for the FN05 series and MN14, compared to that from the default ARG00. Figure $11 \mathrm{com}-$ pares the spatial distributions of the simulated CDNC in warm clouds from ARG00, FN05 series, MN14, and the MODIS-derived CDNC from Bennartz (2007). As shown in Fig. 11, the lower Corr and higher NMEs for the FN05 series 

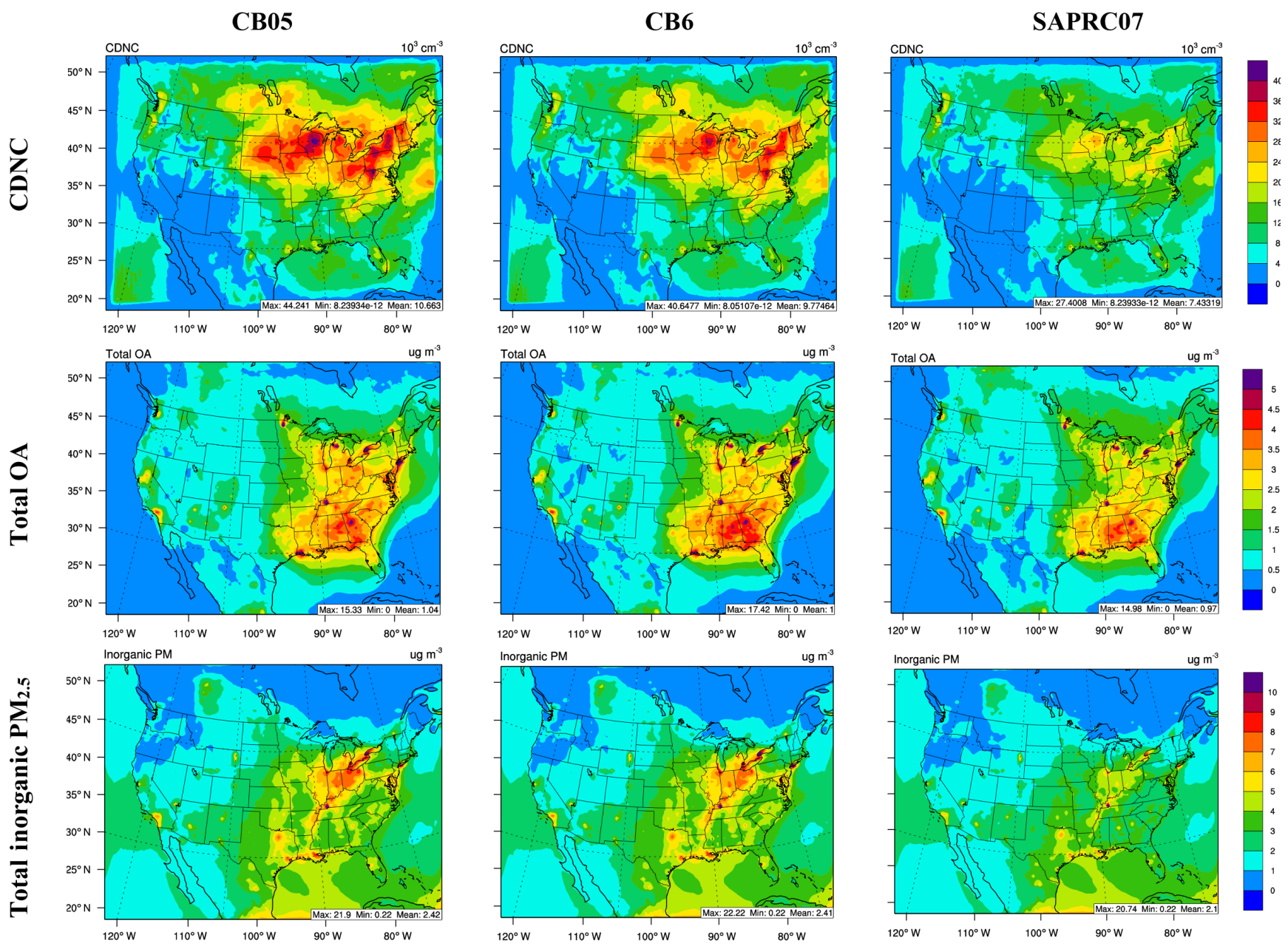

Figure 10. Spatial plots of total column CDNC, total surface OA, and total inorganic $\mathrm{PM}_{2.5}$ concentrations from simulations with different gas-phase mechanisms.

compared to ARG00 shown in Table 9, and also compared to ARG00, are due to the large overpredictions over the northeastern US but underpredictions over other parts of the domain. The simulated CDNC from the default ARG00 case is similar to that from Bennartz (2007) over the eastern US; the underpredictions are mainly over the western US and over the ocean because of the known bias when large $\mathrm{CCN}$ are not present (Morales Betancourt and Nenes, 2014). The simulations with the FN05 series increase CDNC where CCN is high, i.e., over the northeastern US, resulting in overpredictions in CDNC over the northeastern US, and does not help to improve CDNC predictions over other parts of the US as well as over the ocean.

Figure 12 compares the simulated $\mathrm{CCN}$ and AOD from the CB05_25\%FF_EM3 + MN14 case with those derived from the MODIS. The model largely underpredicts $\mathrm{CCN}$, especially over the western part of the domain, which also explains the large underprediction of CDNC over the western part of the domain. Condensation of the available water va- por occurs over $\mathrm{CCN}$ which are concentrated over the northeastern US, resulting in overpredictions of CDNC over the northeastern US. The lack of CCN over the ocean and the western part of the domain is related to the underpredictions of AOD over the same areas. This indicates biases in number (and probably mass) concentrations of column PM concentrations, especially over the ocean and western US. $\mathrm{PM}_{2.5}$ and $\mathrm{PM}_{10}$ observational data are available over the surface and are both underpredicted; however, there are no observational data for column concentrations of $\mathrm{PM}_{2.5}$ and $\mathrm{PM}_{10}$ for evaluation. Improving the spatial distribution and magnitude of emissions for PM species and precursors for the model layers at the surface and above the surface can help improve $\mathrm{AOD}$ and $\mathrm{CCN}$ predictions, and therefore $\mathrm{CDNC}$ predictions.

\section{Summary and conclusions}

Current regional air quality models including WRF/Chem have large uncertainties in modeling OA and aerosol-cloud 

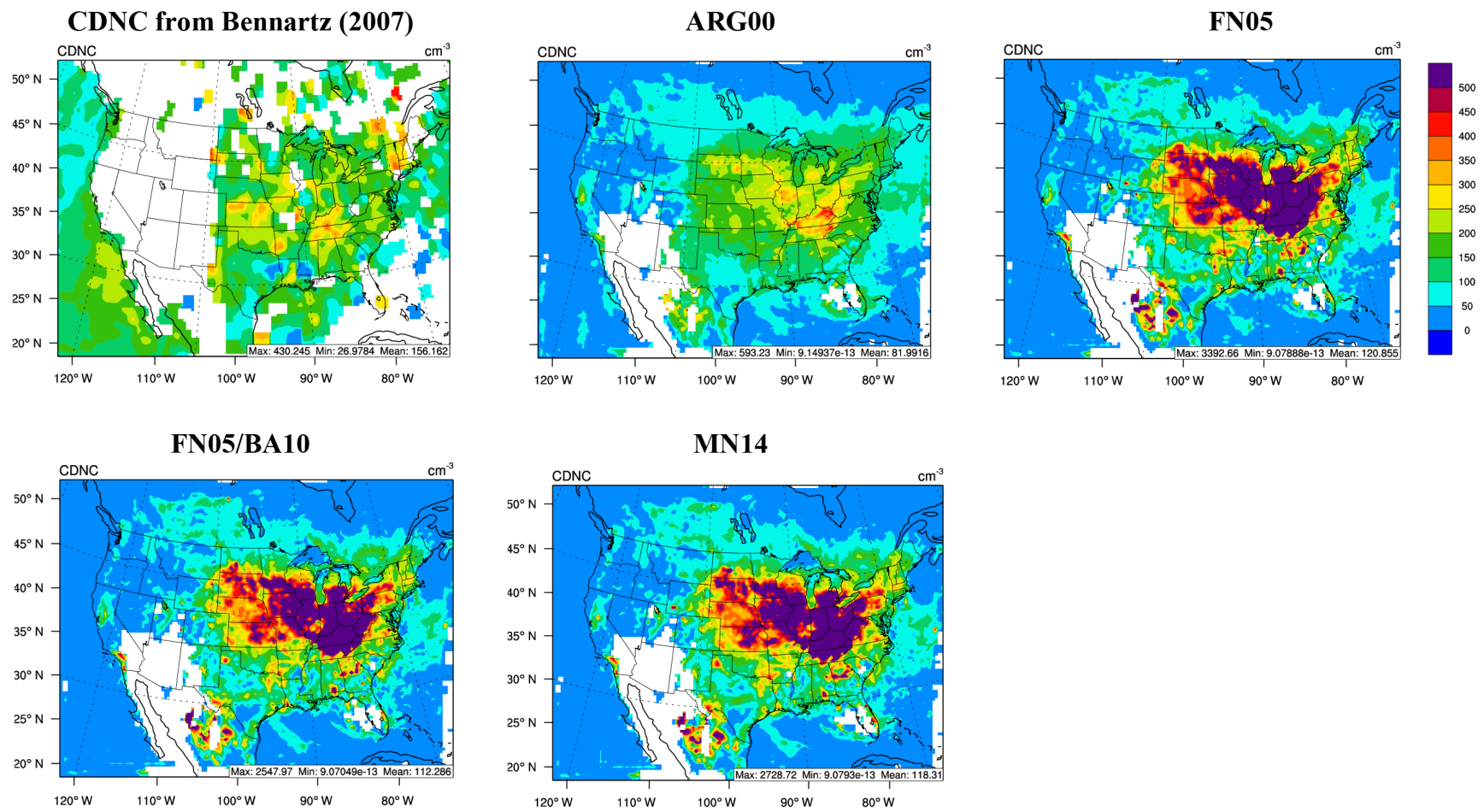

Figure 11. Spatial plots for MODIS-derived CDNC from Bennartz (2007) and simulated in-cloud column CDNC from CB05_25\%FF_EM3 ARG00, FN series, and MN14 from May to June 2010.
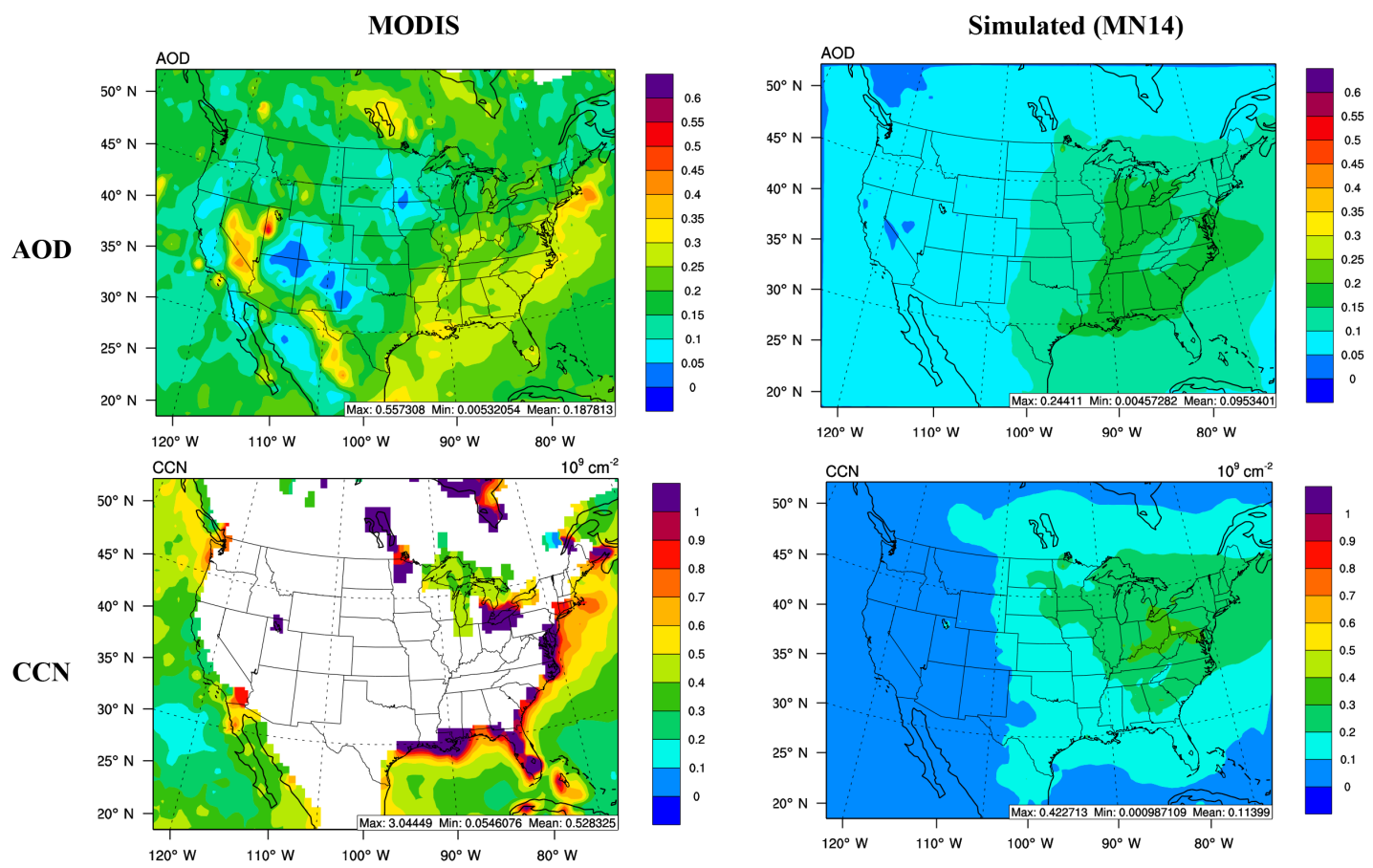

Figure 12. Spatial plots of MODIS CCN and AOD against simulated CCN and AOD from MN14 with CB05_25\%FF_EM3. 
Table 7. Statistics for max $1 \mathrm{~h}$ and $\max 8 \mathrm{~h} \mathrm{O}_{3}$ for simulations with different gas phases against CASTNET and AQS for May to June 2010 .

\begin{tabular}{|c|c|c|c|c|c|}
\hline Case & Mean Obs & Mean Sim & Corr & NMB $(\%)$ & $\operatorname{NME}(\%)$ \\
\hline \multicolumn{6}{|c|}{ CASTNET Max $1 \mathrm{~h} \mathrm{O} 3$} \\
\hline CB05-25\%FF-EM3 & 51.8 & 43.3 & 0.54 & -16.3 & 21.9 \\
\hline CB6-25\%FF-EM3 & 51.8 & 41.9 & 0.52 & -19.1 & 24.1 \\
\hline SAPRC07-25\%FF-EM3 & 51.8 & 48.3 & 0.51 & -6.7 & 21.1 \\
\hline \multicolumn{6}{|c|}{ CASTNET Max $8 \mathrm{~h} \mathrm{O}_{3}$} \\
\hline CB05-25\%FF-EM3 & 47.4 & 43.0 & 0.54 & -9.3 & 18.9 \\
\hline CB6-25\%FF-EM3 & 47.4 & 41.8 & 0.53 & -11.8 & 20.6 \\
\hline SAPRC07-25\%FF-EM3 & 47.4 & 47.9 & 0.50 & 1.0 & 19.8 \\
\hline \multicolumn{6}{|c|}{ AQS Max $1 \mathrm{~h} \mathrm{O}_{3}$} \\
\hline CB05-25\%FF-EM3 & 51.0 & 49.9 & 0.55 & -2.1 & 18.2 \\
\hline CB6-25\%FF-EM3 & 51.0 & 51.5 & 0.43 & 1.0 & 20.8 \\
\hline SAPRC07-25\%FF-EM3 & 51.0 & 59.3 & 0.44 & 16.4 & 26.1 \\
\hline \multicolumn{6}{|c|}{ AQS Max $8 \mathrm{~h} \mathrm{O}_{3}$} \\
\hline CB05-25\%FF-EM3 & 46.2 & 46.0 & 0.54 & -0.4 & 18.6 \\
\hline CB6-25\%FF-EM3 & 46.2 & 47.4 & 0.47 & 2.6 & 20.3 \\
\hline SAPRC07-25\%FF-EM3 & 46.2 & 53.7 & 0.46 & 16.3 & 25.4 \\
\hline \multicolumn{6}{|c|}{ IMPROVE $\mathrm{PM}_{2.5}$} \\
\hline CB05-25\%FF-EM3 & 4.9 & 3.8 & 0.64 & -22.0 & 40.6 \\
\hline CB6-25\%FF-EM3 & 4.9 & 4.1 & 0.65 & -16.5 & 39.6 \\
\hline SAPRC07-25\%FF-EM3 & 4.9 & 3.5 & 0.60 & -28.5 & 42.9 \\
\hline \multicolumn{6}{|c|}{$\mathrm{STN} \mathrm{PM}_{2.5}$} \\
\hline CB05-25\%FF-EM3 & 11.1 & 8.8 & 0.48 & -20.6 & 40.7 \\
\hline CB6-25\%FF-EM3 & 11.1 & 10.0 & 0.37 & -9.3 & 44.3 \\
\hline SAPRC07-25\%FF-EM3 & 11.1 & 7.7 & 0.40 & -30.5 & 45.2 \\
\hline \multicolumn{6}{|c|}{ AQS $\mathrm{PM}_{10}$} \\
\hline CB05-25\%FF-EM3 & 24.6 & 7.3 & 0.08 & -70.2 & 73.5 \\
\hline CB6-25\%FF-EM3 & 24.6 & 8.0 & 0.09 & -67.7 & 71.8 \\
\hline SAPRC07-25\%FF-EM3 & 24.6 & 6.9 & 0.09 & -71.9 & 74.8 \\
\hline
\end{tabular}

Table 8. Statistics for model evaluation for simulated CDNC against MODIS-derived CDNC from Bennartz (2007). All cases use the GrellFreitas cumulus parameterization.

\begin{tabular}{lcrccc}
\hline Case & Mean Obs & Mean Sim & Corr & NMB (\%) & NME (\%) \\
\hline CB05-SORG-DH & 162.1 & 96.0 & 0.28 & -40.8 & 50.4 \\
CB05-VBS-DH & 162.1 & 106.0 & 0.28 & -34.6 & 50.6 \\
CB05-POA-DH & 162.1 & 115.0 & 0.29 & -29.1 & 47.4 \\
CB05-POA & 162.1 & 117.3 & 0.29 & -27.7 & 47.3 \\
CB05-10\%FF & 162.1 & 117.1 & 0.29 & -27.8 & 47.2 \\
CB05-25\%-FF & 162.1 & 116.4 & 0.29 & -28.2 & 47.3 \\
CB05-50\%-FF & 162.1 & 114.7 & 0.29 & -29.2 & 47.4 \\
CB05-25\%FF-EM3 & 162.1 & 116.2 & 0.29 & -28.3 & 47.3 \\
CB6-25\%FF-EM3 & 162.1 & 110.4 & 0.30 & -31.9 & 47.3 \\
SAPRC07-25\%FF-EM3 & 162.1 & 77.3 & 0.26 & -52.3 & 55.8 \\
\hline
\end{tabular}


Table 9. Statistics for simulated CDNC for CB05-25\%FF-EM3 against MODIS-derived CDNC from Bennartz (2007) for May to June 2010. All cases use the MSKF cumulus parameterization.

\begin{tabular}{lcccrc}
\hline Case & Mean Obs & Mean Sim & Corr & NMB (\%) & NME (\%) \\
\hline ARG00 & 162.1 & 104.8 & 0.31 & -35.4 & 49.9 \\
FN05 & 162.1 & 173.8 & 0.26 & 7.1 & 93.0 \\
FN05/BA10 & 162.1 & 160.8 & 0.27 & -0.8 & 87.9 \\
MN14 & 162.1 & 168.9 & 0.27 & 4.2 & 89.6 \\
\hline
\end{tabular}

feedback mechanisms such as the aerosol activation process. Compared to the traditional OA method, the VBS treatment helps to improve OA predictions by reducing the underpredictions of OA. By including a semivolatile POA treatment, using a semi-empirical formation of Epstein et al. (2010) for $H_{\text {vap }}$, including $25 \%$ fragmentation and functionalization as well as including additional SVOC and IVOC emissions, the VBS treatment in WRF/Chem simulates the atmospheric OA formation processes more realistically and can perform relatively well in predictions of $\mathrm{OC}$ and TC against IMPROVE and STN. POA/OA ratios for the CB05_25\%FF_EM3 and CB05_FF50\% treatments are within the range of POA / OA ratios of $\sim 0.15$ to 0.40 from literature. Compared to the simulation with default SORGAM SOA module, the simulations with various new VBS treatments also give better agreement with observed SOA at Bakersfield and Pasadena during the CalNex field campaign from May to June 2010. However, biases exist in those simulations with the VBS treatments for several possible reasons, including underestimated POA emissions, underpredicted VOC concentrations, and differences in the SOA precursors used in the model and those contributing to the observed SOA concentrations. The simulations with different gas-phase mechanisms (i.e., CB05, CB6, and SAPRC07) produce in general different ASOA and BSOA concentrations. SAPRC07 produces the highest $\mathrm{O}_{3}$ mixing ratios, while $\mathrm{CB} 6$ produces the lowest $\mathrm{OH}+\mathrm{HO}_{2}$ mixing ratios. CB6 also performs the best when evaluated against IMPROVE PM2.5 while CB05 performs the best when evaluated against STN PM2.5 concentrations. All three cases perform poorly against AQS $\mathrm{PM}_{10}$ evaluation. Due to the significant differences between $\mathrm{O}_{3}, \mathrm{OH}$, and $\mathrm{HO}_{2}$ mixing ratios for the three gas-phase mechanisms, inorganic PM concentrations vary widely, especially between the Carbon Bond mechanisms (CB05 and CB6) and SAPRC07, resulting in significantly different predictions of CDNC. The CDNC predictions do not vary much among simulations with $\mathrm{CB} 05$ and different VBS treatments, for example, for simulations with nonvolatile versus semivolatile POA, and with and without fragmentation and functionalization treatments. The simulation with SAPRC07 produces the lowest CDNC compared to those with CB05 and CB6, due to the lowest inorganic $\mathrm{PM}$ number and mass concentrations resulting from the lowest $\mathrm{OH}$ and $\mathrm{HO}_{2}$ mixing ratios among all simulations. $\mathrm{CB} 05$ gives the best performances when evaluated against CASTNET and AQS ozone mixing ratios, STN $\mathrm{PM}_{2.5}$ concentrations, and MODIS CDNC.

With the default ARG00 treatment in the model, in general, all simulations with VBS treatments underpredict the MODIS-derived CDNC by Bennartz (2007). By including the FN05 series (i.e., FN05, FN05/BA10, and MN14), the underpredictions for CDNC are greatly reduced. However, the correlation coefficient and errors are worse with the FN05 series, with large overpredictions over the northeastern US, where $\mathrm{CCN}$ is high. The model performs poorly for AOD and $\mathrm{CCN}$, likely due to inaccuracies in spatial distribution and magnitudes of PM and PM precursor emissions in the model layers at the surface and above the surface. The CDNC predictions can be improved by improving AOD and CCN underpredictions over the western US and over the ocean.

Code and data availability. The WRF/Chem v3.7.1 code used in this paper will be available upon request. The inputs including the meteorological files, meteorological initial and boundary conditions, chemical initial and boundary conditions, model setup and configuration, and the name-list setup and instructions on how to run the simulations for a 1-day test case, as well as a sample output for a 1-day test, can be provided upon request.

Competing interests. The authors declare that they have no conflict of interest.

Acknowledgements. This study is funded in part by the National Science Foundation EaSM program (AGS-1049200) at NCSU and in part under Assistance Agreement no. RD835871 awarded by the US Environmental Protection Agency to Yale University. It has not been formally reviewed by EPA. The views expressed in this document are solely those of the SEARCH Center and do not necessarily reflect those of the Agency. EPA does not endorse any products or commercial services mentioned in this publication. The emissions are taken from the 2008 NEI-derived emissions for 2010 provided by the US EPA, Environment Canada, and Mexican Secretariat of the Environment and Natural Resources (Secretaría de Medio Ambiente y Recursos Naturales-SEMARNAT) and National Institute of Ecology (Instituto Nacional de Ecología-INE) as part of the Air Quality Model Evaluation International Initiative (AQMEII). The authors acknowledge use of the WRF-Chem preprocessor tool mozbc, provided by the Atmospheric Chemistry Observations and Modeling Lab (ACOM) of NCAR, and the script to generate initial and boundary conditions for WRF based on CESM results, provided by Ruby Leung, PNNL. This work also used the Stampede Extreme Science and Engineering Discovery Environment (XSEDE) high-performance computing support, which is supported by the National Science Foundation grant number ACI-1053575. The authors also acknowledge high-performance computing support from Yellowstone (ark:/85065/d7wd3xhc) provided by NCAR's Computational and Information Systems Laboratory, sponsored by the National Science Foundation and Information Systems Laboratory. 
Edited by: G. A. Folberth

Reviewed by: two anonymous referees

\section{References}

Abdul-Razzak, H. and Ghan, S. J.: A parameterization of aerosol activation 2. Multiple aerosol types, J. Geophys. Res., 105, 6837 $-6844,2000$.

Ackermann, I. J., Hass, H., Memmesheimer, M., Ebel, A., Binkowski, F. S., and Shankar, U.: Modal aerosol dynamics model for Europe: Development and first applications, Atmos. Environ., 32, 2981-2999, 1998.

Ahmadov, R., McKeen, S. A., Robinson, A. L., Bareini, R., Middlebrook, A. M., De Gouw, J. A., Meagher, J., Hsie, E.-Y., Edgerton, E., Shaw, S., and Trainer, M.: A volatility basis set model for summertime secondary organic aerosols over the eastern United States in 2006, J. Geophys. Res., 117, D06301, https://doi.org/10.1029/2011JD016831, 2012.

Aitken, A. C., DeCarlo, P. F., Kroll, A., Worsnop, D. R., Huffman, J. A., Docherty, K. S., Ulbrich, I. M., Mohr, C., Kimmel, J. R., Sueper, D., Sun, Y., Zhang, Q., Trimborn, A., Northway, M., Ziemann, P. J., Canagaratna, M. R., Onasch, T. B., Alfarra, M. R., Prevot, A. S. H., Dommen, J., Duplissy, J., Metzger, A., Baltensperger, U., and Jimenez, J. L.: $\mathrm{O} / \mathrm{C}$ and OM / OC Ratios of primary, secondary, and ambient organic aerosols with high-resolution time-of-flight aerosol mass spectrometry, Environ. Sci. Technol., 42, 4478-4485, https://doi.org/10.1021/es703009q, 2008.

Atkinson, R., Baulch, D. L., Cox, R. A., Crowley, J. N., Hampson, R. F., Hynes, R. G., Jenkin, M. E., Rossi, M. J., Troe, J., and IUPAC Subcommittee: Evaluated kinetic and photochemical data for atmospheric chemistry: Volume II - gas phase reactions of organic species, Atmos. Chem. Phys., 6, 3625-4055, https://doi.org/10.5194/acp-6-3625-2006, 2006.

Baker, K. R., Carlton, A. G., Kleindienst, T. E., Offenberg, J. H., Beaver, M. R., Gentner, D. R., Goldstein, A. H., Hayes, P. L., Jimenez, J. L., Gilman, J. B., de Gouw, J. A., Woody, M. C., Pye, H. O. T., Kelly, J. T., Lewandowski, M., Jaoui, M., Stevens, P. S., Brune, W. H., Lin, Y.-H., Rubitschun, C. L., and Surratt, J. D.: Gas and aerosol carbon in California: comparison of measurements and model predictions in Pasadena and Bakersfield, Atmos. Chem. Phys., 15, 5243-5258, https://doi.org/10.5194/acp15-5243-2015, 2015.

Barahona, D. and Nenes, A.: Parameterization of cloud droplet formation in large-scale models: Including effects of entrainment, J. Geophys. Res., 112, D16206, https://doi.org/10.1029/2007JD008473, 2007.

Barahona, D., West, R. E. L., Stier, P., Romakkaniemi, S., Kokkola, H., and Nenes, A.: Comprehensively accounting for the effect of giant $\mathrm{CCN}$ in cloud activation parameterizations, Atmos. Chem. Phys., 10, 2467-2473, https://doi.org/10.5194/acp10-2467-2010, 2010.

Bennartz, R.: Global assessment of marine boundary layer cloud droplet number concentration from satellite, J. Geophys. Res.Atmos., 112, D02201, https://doi.org/10.1029/2006JD007547, 2007.

Bergstrom, R., Denier van der Gon, H. A. C., Prevot, A. S. H., Yttri, K. E., and Simpson, D.: Modelling of organic aerosols over Eu- rope (2002-2007) using a volatility basis set (VBS) framework: application of different assumptions regarding the formation of secondary organic aerosol, Atmos. Chem. Phys., 12, 8499-8527, https://doi.org/10.5194/acp-12-8499-2012, 2012.

Boucher, O., Randall, D., Artaxo, P., Bretherton, C., Feingold, G., Forster, P., Kerminen, V.-M., Kondo, Y., Liao, H., Lohmann, U., Rasch, P., Satheesh, S.K., Sherwood, S., Stevens, B., and Zhang, X. Y.: Clouds and Aerosols, in: Climate Change 2013: The Physical Science Basis, Contribution of Working Group I to the Fifth Assessment Report of the Intergovernmental Panel on Climate Change, edited by: Stocker, T. F., Qin, D., Plattner, G.-K., Tignor, M., Allen, S. K., Boschung, J., Nauels, A., Xia, Y., Bex, V., and Midgley, P. M., Cambridge University Press, Cambridge, UK and New York, NY, USA, 2013.

Campbell, P., Zhang, Y., Yahya, K., Wang, K., Hogrefe, C., Pouliot, G., Knote, C., Hodzic, A., San Jose, R., Perez, J. L., Jimenez Guerrero, P., Baro, R., and Makar, P.: A multi-model assessment for the 2006 and 2010 simulations under the Air Quality Model Evaluation International Initiative (AQMEII) phase 2 over North America: Part I. Indicators of the sensitivity of $\mathrm{O}_{3}$ and $\mathrm{PM}_{2.5}$ formation regimes, Atmos. Environ., 115, 569-586, 2015.

Carter, W. P. L.: Implementation of the SAPRC-99 chemical mechanism into the models-3 framework, Report to the US EPA, http://www.cert.ucr.edu/ carter/pubs/s99mod3.pdf (last access: 19 February 2016), 2000.

Carter, W. P. L.: Development of the SAPRC07 chemical mechanism, Atmos. Environ., 44, 5324-5335, https://doi.org/10.1016/j.atmosenv.2010.01.026, 2010.

Chan, A. W. H., Kautzman, K. E., Chhabra, P. S., Surratt, J. D., Chan, M. N., Crounse, J. D., Kürten, A., Wennberg, P. O., Flagan, R. C., and Seinfeld, J. H.: Secondary organic aerosol formation from photooxidation of naphthalene and alkylnaphthalenes: implications for oxidation of intermediate volatility organic compounds (IVOCs), Atmos. Chem. Phys., 9, 3049-3060, https://doi.org/10.5194/acp-9-3049-2009, 2009.

Cleveland, M. J., Ziemba, L. D., Griffin, R. J., Dibb, J. E., Anderson, C. H., Lefer, B., and Rappengluck, B.: Characterization of urban aerosol using aerosol mass spectrometry and proton nuclear magnetic resonance spectroscopy, Atmos. Environ., 54, 511-518, https://doi.org/10.1016/j.atmosenv.2012.02.074, 2012.

Donahue, N. M., Robinson, A. L., Stanier, C. O., and Pandis, S. N.: Coupled partitioning, dilution and chemical aging of semivolatile organics, Environ. Sci. Technol., 40, 2635-2643, 2006.

Donahue, M. N., Robinson, A. L., and Pandis, S. N.: Atmospheric organic particulate matter: From smoke to secondary organic aerosol, Atmos. Environ., 43, 94-106, 2009.

Emmons, L. K., Walters, S., Hess, P. G., Lamarque, J.-F., Pfister, G. G., Fillmore, D., Granier, C., Guenther, A., Kinnison, D., Laepple, T., Orlando, J., Tie, X., Tyndall, G., Wiedinmyer, C., Baughcum, S. L., and Kloster, S.: Description and evaluation of the Model for Ozone and Related chemical Tracers, version 4 (MOZART-4), Geosci. Model Dev., 3, 43-67, https://doi.org/10.5194/gmd-3-43-2010, 2010.

ENVIRON: User's guide to the comprehensive air quality model with extensions, version 6, available at: http://www.camx.com/ files/camxusersguide_v6-10.pdf (last access: 19 June 2017), 2013. 
Epstein, S. A., Riipinen, I., and Donahue, N. M.: A semiempirical correlation between enthalpy of vaporization and saturation concentration for organic aerosol, Environ. Sci. Technol., 44, 743748, 2010.

Farina, S. C., Adams, P. J., and Pandis, S. N.: Modeling global secondary organic aerosol formation and processing with the volatility basis set: Implications for anthropogenic secondary organic aerosol, J. Geophys. Res., 115, D09202, https://doi.org/10.1029/2009JD013046, 2010.

Fountoukis, C. and Nenes, A.: Continued development of a cloud droplet formation parameterization for global climate models, J. Geophys. Res., 110, D11212, https://doi.org/10.1029/2004JD005591, 2005.

Gantt, B., He, J., Zhang, X., Zhang, Y., and Nenes, A.: Incorporation of advanced aerosol activation treatments into CESM/CAM5: model evaluation and impacts on aerosol indirect effects, Atmos. Chem. Phys., 14, 7485-7497, https://doi.org/10.5194/acp14-7485-2014, 2014.

Ghan, S. J., Abdul-Razzak, H., Nenes, A., Ming, Y., Liu, X., Ovchinnikov, M., Shipway, B., Meskhidze, N., Xu, J., and Shi, X.: Droplet nucleation: Physically-based parameterizations and comparative evaluation, J. Adv. Model. Earth Syst., 3, M10001, https://doi.org/10.1029/2011ms000074, 2011.

Glotfelty, T., He, J., and Zhang, Y.: Improving Organic Aerosol Treatments in CESM/CAM5: Development, Application, and Evaluation, Journal of Advances in Modeling Earth Systems, https://doi.org/10.1002/2016MS000874, online first, 2017.

Gong, S., Barrie, L. A., and Blanchet, J. P.: Modeling sea salt aerosols in the atmosphere: 1. Model development, J. Geophys. Res., 102, 3805-3818, https://doi.org/10.1029/96JD02953, 1997.

Grell, G. A. and Freitas, S. R.: A scale and aerosol aware stochastic convective parameterization for weather and air quality modeling, Atmos. Chem. Phys., 14, 5233-5250, https://doi.org/10.5194/acp-14-5233-2014, 2014.

Grieshop, A. P., Logue, J. M., Donahue, N. M., and Robinson, A. L.: Laboratory investigation of photochemical oxidation of organic aerosol from wood fires 1: measurement and simulation of organic aerosol evolution, Atmos. Chem. Phys., 9, 1263-1277, https://doi.org/10.5194/acp-9-1263-2009, 2009.

Guenther, A., Karl, T., Harley, P., Wiedinmyer, C., Palmer, P. I., and Geron, C.: Estimates of global terrestrial isoprene emissions using MEGAN (Model of Emissions of Gases and Aerosols from Nature), Atmos. Chem. Phys., 6, 3181-3210, https://doi.org/10.5194/acp-6-3181-2006, 2006.

Hallquist, M., Wenger, J. C., Baltensperger, U., Rudich, Y., Simpson, D., Claeys, M., Dommen, J., Donahue, N. M., George, C., Goldstein, A. H., Hamilton, J. F., Herrmann, H., Hoffmann, T., Iinuma, Y., Jang, M., Jenkin, M. E., Jimenez, J. L., Kiendler-Scharr, A., Maenhaut, W., McFiggans, G., Mentel, Th. F., Monod, A., Prévôt, A. S. H., Seinfeld, J. H., Surratt, J. D., Szmigielski, R., and Wildt, J.: The formation, properties and impact of secondary organic aerosol: current and emerging issues, Atmos. Chem. Phys., 9, 5155-5236, https://doi.org/10.5194/acp9-5155-2009, 2009.

Hayes, P. L., Ortega, A. M., Cubison, M. J., Froyd, K. D., Zhao, Y., Cliff, S. S., Hu, W. W., Toohey, D. W., Flynn, J. H., Lefer, B. L., Grossberg, N., Alvarez, S., Rappengluck, B., Taylor, J. W., Allan, J. D., Holloway, J. S., Gilman, J. B., Kuster, W.
C., de Gouw, J. A., Massoli, P., Zhang, X., Liu, J., Weber, R. J., Corrigan, A. L., Russell, L. M., Isaacman, G., Worton, D. R., Kreisberg, N. M., Goldstein, A. H., Thalman, R., Waxman, E. M., Volkamer, R., Lin, Y. H., Surratt, J. D., Kleindienst, T. E., Offenberg, J. H., Dusanter, S., Griffith, S., Stevens, P. S., Brioude, J., Angevine, W. M., and Jimenez, J. L.: Organic aerosol composition and sources in Pasadena, California during the 2010 CalNex campaign, J. Geophys. Res.-Atmos., 118, 9233-9257, https://doi.org/10.1002/jgrd.50530, 2013.

He, J., and Zhang, Y.: Improvement and further development in CESM/CAM5: gas-phase chemistry and inorganic aerosol treatments, Atmos. Chem. Phys., 14, 9171-9200, https://doi.org/10.5194/acp-14-9171-2014, 2014.

Henderson, B. H., Akhtar, F., Pye, H. O. T., Napelenok, S. L., and Hutzell, W. T.: A database and tool for boundary conditions for regional air quality modeling: description and evaluation, Geosci. Model Dev., 7, 339-360, https://doi.org/10.5194/gmd-7339-2014, 2014.

Hodzic, A., Jimenez, J. L., Madronich, S., Canagaratna, M. R., DeCarlo, P. F., Kleinman, L., and Fast, J.: Modeling organic aerosols in a megacity: potential contribution of semi-volatile and intermediate volatility primary organic compounds to secondary organic aerosol formation, Atmos. Chem. Phys., 10, 5491-5514, https://doi.org/10.5194/acp-10-5491-2010, 2010.

Hong, S.-Y: : A new stable boundary-layer mixing scheme and its impact on the simulated East Asian summer monsoon, Q. J. Roy. Meteorol. Soc., 136, 1481-1496, https://doi.org/10.1002/qj.665, 2010.

Hong, S.-Y., Noh, Y., and Dudhia, J.: A new vertical diffusion package with an explicit treatment of entrainment processes, Mon. Weather Rev., 134, 2318-2341, 2006.

Jathar, S. H., Farina, S. C., Robinson, A. L., and Adams, P. J.: The influence of semi-volatile and reactive primary emissions on the abundance and properties of global organic aerosol, Atmos. Chem. Phys., 11, 7727-7746, https://doi.org/10.5194/acp11-7727-2011, 2011.

Jimenez, J. L., Canagaratna, M. R., Donahue, N. M., Prevot, A. S. H., Zhang, Q., Kroll, J. H., DeCarlo, P. F., Allan, J. D., Coe, H., Ng, N. L., Aiken, A. C., Docherty, K. ., Ulbrich, I. M., Grieshop, A. P., Robinson, A. L., Duplissy, J., Smith, J. D., Wilson, K. R., Lanz, V. A., Hueglin, C., Sun, Y. L., Tian, J., Laaksonen, A., Raatikainen, T., Rautiainen, J., Vaattovaara, P., Ehn, M., Kulmala, M., Tomlinson, J. M., Collins, D. R., Cubison, M. J., Dunlea, E. J., Huffman, J. A., Onasch, T. B., Alfarra, M. R., Williams, P. I., Bower, K., Kondo, Y., Schneider, J., Drewnick, F., Borrman, S., Weimer, S., Demerjian, K., Salcedo, D., Cottrell, L., Griffin, R., Takami, A., Miyoshi, T., Hatakeyama, S., Shimono, A., Sun, J. Y., Zhang, Y. M., Dzepina, K., Kimmel, J. R., Sueper, D., Jayne, J. T., Herndon, S. C., Trimborn, A. M., Williams, L. R., Wood, E. C., Middlebrook, A. M., Kolb, C. E., Baltensperger, U., and Worsnop, D. R.: Evolution of Organic Aerosols in the Atmosphere, Science, 326, 1525-1529, https://doi.org/10.1126/science.1180353, 2009.

Jones, S. and Creighton, G.: AFWA dust emission scheme for WRF/Chem-GOCART, 2011 WRF workshop, 20-24 June 2011, Boulder, CO, USA, 2011.

Kim, Y., Sartelet, K., and Seigneur, C.: Formation of secondary aerosols over Europe: comparison of two gas-phase mechanisms, 
Atmos. Chem. Phys., 11, 583-598, https://doi.org/10.5194/acp11-583-2011, 2011.

Kleindienst, T. E., Jaoui, M., Lewandowski, M., Offenberg, J. H., and Docherty, K. S.: The formation of SOA and chemical tracer compounds from the photooxidation of naphthalene and its methyl analogs in the presence and absence of nitrogen oxides, Atmos. Chem. Phys., 8711-8726, https://doi.org/10.5194/acp12-8711-2012, 2012.

Kumar, P., Nenes, A., and Sokolik, I. N.: Importance of adsorption for $\mathrm{CCN}$ activity and hygroscopic properties of mineral dust aerosol, Geophy. Res. Lett., 36, L24804, https://doi.org/10.1029/2009GL040827, 2009.

Laaksonen, A., Malila, J., Nenes, A., Hung, H., and Chen, J. P.: Surface fractal dimension, water adsorption efficiency, and cloud nucleation activity of insoluble aerosol, Nat. Sci. Rep., 6, 25504, https://doi.org/10.1038/srep25504, 2016.

Lane, T. E., Donahue, N. M., and Pandis, S. N.: Simulating secondary organic aerosol formation using the volatility basis-set approach in a chemical transport model, Atmos. Environ., 42, 7439-7451, 2008.

Lewandowski, M., Piletic, I. R., Kleindienst, T. E., Offenberg, J. H., Beaver, M. R., Jaoui, M., Docherty, K. S., and Edney, E. O.: Secondary organic aerosol characterisation at field sites across the United States during the springsummer period, Int. J. Environ. Anal. Chem., 93, 1084-1103, https://doi.org/10.1080/03067319.2013.803545, 2013.

Li, J., Zhang, H., and Ying, Q.: Comparison of the SAPRC07 and SAPRC99 photochemical mechanisms during a high ozone episode in Texas: Differences in concentrations, OH budget and relative response factors, Atmos. Environ., 25-35, https://doi.org/10.1016/j.atmosenv.2012.02.034, 2012.

Luecken, D. J., Phillips, S., Sarwar, G., and Jang, C.: Effects of using the CB05 versus SAPRC99 versus CB4 chemical mechanism on model predictions: Ozone and gas-phase photochemical precursor concentrations, Atmos. Environ., 42, 5805-5820, 2008.

May, A. A., Presto, A. A., Hennigan, C. J., Nguyen, N. T., Gordon, T. D., and Robinson, A. L.: Gas-particle partitioning of primary organic aerosol emissions: (1) Gasoline vehicle exhaust, Atmos. Environ., 77, 128-139, 2013a.

May, A. A., Presto, A. A., Hennigan, C. J., Nguyen, N. T., Gordon, T. D., and Robinson, A. L.: Gas-particle partitioning of primary organic aerosol emissions: (2) Diesel vehicles, Environ. Sci. Technol., 47, 8288-8296, 2013b.

May, A. A., Levin, E. J. T., Hennigan, C. J., Riipinen, I., Lee, T., Collett Jr., J. R., Jimenez, J. L., Kreidenweis, S. M., and Robinson, A. L.: Gas-particle partitioning of primary organic aerosol emissions, 3. Biomass burning, J. Geophys. Res., 118, $11327-$ 11338, https://doi.org/10.1002/jgrd.50828, 2013c.

Morales Betancourt, R. and Nenes, A.: Droplet activation parameterization: the population-splitting concept revisited, Geosci. Model Dev., 7, 2345-2357, https://doi.org/10.5194/gmd-7-23452014, 2014.

Morrison, H., Thompson, G., and Tatarskii, V.: Impact of cloud microphysics on the development of trailing stratiform precipitation in a simulated squall line: Comparison of One- and Two-Moment Schemes, Mon. Weather Rev., 137, 991-1007, 2009.

Murphy, B. N. and Pandis, S. N.: Simulating the formation of semivolatile primary and secondary organic aerosol in a regional chemical transport model, Environ. Sci. Technol., 2009, 47224728, 2009.

Myhre, G., Shindell, D., Breon, F.-M., Collins, W., Fuglestvedt, F., Huang, J., Koch, D., Lamarque, J.-F., Lee, D., Mendoza, B., Nakajima, T., Robock, A., Stephens, G., Takemura, T., and Zhan, H.: Anthropogenic and Natural Radiative Forcing in: Climate Change 2013: The Physical Science Basis, Contribution of Working Group I to the Fifth Assessment Report of the Intergovernmental Panel on Climate Change, edited by: Stocker, T. F., Qin, D., Plattner, G.-K., Tignor, M., Allen, S. K., Boschung, J., Nauels, A., Xia, Y., Bex, V., and Midgley, P. M., Cambridge University Press, Cambridge, UK and New York, NY, USA, 2013.

Nenes, A. Ghan, S., Abdul-Razzak, H., Chuang, P. Y., and Seinfeld, J.: Kinetic limitations on cloud droplet formation and impact on cloud albedo, Tellus B, 53, 133-149, 2001.

Nopmongcol, U., Koo, B., Tai, E., Jung, J., Piyachaturawat, P., Emery, C., Yarwood, G., Pirovano, G., Mitsakou, C., and Kallos, G.: Modeling Europe with CAMx for the Air Quality Model Evaluation International Initiative (AQMEII), Atmos. Environ., 53, 177-185, 2012.

Odum, J. R., Hoffman, T., Bowman, F., Collins, D., Flagan, R. C., and Seinfeld, J. H.: Gas/Particle Partitioning and Secondary Organic Aerosol Yields, Environ. Sci. Technol., 30, 2580-2585, https://doi.org/10.1021/es950943+, 1996.

Pouliot, G., van der Gon, H. D., Kuenen, J., Makar, P., Zhang, J., and Moran, M.: Analysis of the emission inventories and model-ready emission datasets for Europe and North America for phase 2 of the AQMEII project, Atmos. Environ., 115, 345$360,2015$.

Pye, H. and Seinfeld, J. H.: A global perspective on aerosol from low-volatility organic compounds, Atmos. Chem. Phys., 10, 4377-4401, https://doi.org/10.5194/acp-10-4377-2010, 2010.

Rao, V., Tooly, L., and Drukenbrod, J.: 2008 National Emissions Inventory: Review, Analysis and Highlights, EPA-454/R-13005, available at: http://www.epa.gov/ttn/chief/net/2008report. pdf (last access: 9 October 2015), 2013.

Robinson, A. L., Donahue, N. M., Shrivastava, M. K., Weitkamp, E. A., Sage, A. M., Grieshop, A. P., Lane, T. E., Pierce, J. R., and Pandis, S. N.: Rethinking Organic Aerosols: Semivolatile emissions and photochemical aging, Science, 315, 1259-1262, 2007.

Sander, S. P., Friedl, R. R., Golden, D. M., Kurylo, M. J., Moortgat, G. K., Wine, P. H., Ravishankara, A. R., Kolb, C. E., Molina, M. J., Finlayson-Pitts, B. J., Huie, R. E., and Orkin, V. L.: Chemical Kinetics and Photochemical Data for use in Atmospheric Studies, Evaluation Number 15, NASA Jet Propulsion Laboratory, available at: http://jpldataeval.jpl.nasa.gov/download.html (last access: 19 June 2017), 2006.

Sander, S. P., Friedl, R. R., Golden, D. M., Kurylo, M. J., Huie, R. E., Orkin, V. L., Moortgat, G. K., Ravishankara, A. R., Kolb, C. E., Molina, M. J., and Finlayson-Pitts, B. J.: Chemical Kinetics and Photochemical Data for use in Atmospheric Studies, Evaluation Number 14, NASA Jet Propulsion Laboratory, available at: http://jpldataeval.jpl.nasa.gov/download.html (last access: 19 June 2017), 2003.

Sarwar, G., Fahey, K., Napelenok, S., Roselle, S., and Mathur, R.: Examining the impact of CMAQ model updates on aerosol sulfate predictions, the 10th Annual CMAS Models-3 User's Conference, October 2011, Chapel Hill, NC, 2011. 
Schell, B., Ackermann, I. J., Hass, H., Binkowski, F. S., and Ebel, A.: Modeling the formation of secondary organic aerosol within a comprehensive air quality model system, J. Geophys. Res., 106, 28275-28293, 2001.

Shearer, S. M., Harley, R. A., Jin, L., and Brown, N. J.: Comparison of SAPRC99 and SAPRC07 mechanisms in photochemical modeling for central California, Atmos. Environ., 46, 205-216, https://doi.org/10.1016/j.atmosenv.2011.09.079, 2012.

Shrivastava, M. K., Lane, T. E., Donahue, N. M., Pandis, S. N., and Robinson, A.L.: Effects of gas particle partitioning and aging of primary emissions on urban and regional organic aerosol concentrations, J. Geophys. Res., 113, D18301, https://doi.org/10.1029/2007JD009735, 2008.

Shrivastava, M., Fast, J., Easter, R., Gustafson Jr., W. I., Zaveri, R. A., Jimenez, J. L., Saide, P., and Hodzic, A.: Modeling organic aerosols in a megacity: comparison of simple and complex representations of the volatility basis set approach, Atmos. Chem. Phys., 11, 6639-6662, https://doi.org/10.5194/acp11-6639-2011, 2011.

Shrivastava, M., Zelenyuk, A., Imre, D., Easter, R., Beranek, J., Zaveri, R. A., and Fast, J.: Implications of low volatility SOA and gas-phase fragmentation reactions on SOA loadings and their spatial and temporal evolution in the atmosphere, J. Geophys. Res.-Atmos., 118, 3328-3342, https://doi.org/10.1002/jgrd.50160, 2013.

Shrivastava, M., Easter, R. C., Liu, X., Zelenyuk, A., Singh, B., Zhang, K., Ma, P.-L., Chand, D., Ghan, S., Jimenez, J. L., Zhang, Q., Fast, J., Rasch, P. J., and Titta, P.: Global transformation and fate of SOA: Implications of low-volatility SOA and gas-phase fragmentation reactions, J. Geophys. Res.-Atmos., 120, 41694195, https://doi.org/10.1002/2014JD022563, 2015.

Stockwell, W., Kirchner, F., Kuhn, M., and Seefeld, S.: A new mechanism for regional atmospheric chemistry modeling, J. Geophys. Res., 102, 25847-25879, 1997.

Tsimpidi, A. P., Karydis, V. A., Zavala, M., Lei, W., Molina, L., Ulbrich, I. M., Jimenez, J. L., and Pandis, S. N.: Evaluation of the volatility basis-set approach for the simulation of organic aerosol formation in the Mexico City metropolitan area, Atmos. Chem. Phys., 10, 525-546, https://doi.org/10.5194/acp-10-5252010, 2010.

Turpin, B. J. and Lim, H.-J.: Species Contributions to $\mathrm{PM}_{2.5}$ Mass concentrations: Revisiting Common Assumptions for Estimating Organic Mass, Aerosol Sci. Tech., 35, 602-610, https://doi.org/10.1080/02786820119445, 2001.

US EPA: 2008 National Emissions Inventory, version 3 Technical Support Document, September 2013, Draft, available at: http://www3.epa.gov/ttn/chief/net/2008neiv3/2008_neiv3_tsd_ draft.pdf (last access: 10 October 2015), 2013.

Wang, K. and Zhang, Y.: Application, evaluation, and process analysis of the US EPA's 2002 Multiple-Pollutant Air Quality Modeling Platform, Atmos. Clim. Sci., 2, 254-289, 2012.

Wang, K., Zhang, Y., Yahya, K., Wu, S.-Y., and Grell, G.: Implementation and initial application of new chemistry-aerosol options in WRF/Chem for simulating secondary organic aerosols and aerosol indirect effects, Atmos. Environ., 115, 716-723, https://doi.org/10.1016/j.atmosenv.2015.12.007, 2015.

Xu, L., Guo, H., Boyd, C. M., Klein, M., Bougiatioti, A., Cerully, K. M., Hite, J. R., Isaacman-VanWertz, G., Kreisberg, N. M., Knote, C., Olson, K., Koss, A., Goldstein, A. H., Hering, S.
V., de Gouw, J., Baumann, K., Lee, S.-H., Nenes, A., Weber, R. J., and $\mathrm{Ng}, \mathrm{N}$. L.: Effects of anthropogenic emissions on aerosol formation from isoprene and monoterpenes in the southeastern United States, P. Natl. Acad. Sci. USA, 112, 37-42, https://doi.org/10.1073/pnas.1417609112, 2015.

Yahya, K., Wang, K., Campbell, P., Glotfelty, T., He, J., and Zhang, Y.: Decadal evaluation of regional climate, air quality and their interactions over the continental US using WRF/Chem version 3.6.1, Geosci. Model Dev., 9, 671-695, https://doi.org/10.5194/gmd-9-671-2016, 2016.

Yahya, K., Wang, K., Campbell, P., Chen, Y., Glotfelty, T., He, J., Pirhalla, M., and Zhang, Y.: Decadal application of WRF/Chem for regional air quality and climate modeling over the U.S. under the representative concentration pathways scenarios. Part 1: Model evaluation and impact of downscaling, Atmos. Environ., 152, 562-583, https://doi.org/10.1016/j.atmosenv.2016.12.029, 2017

Yarwood, G., Rao, S., Yocke, M., and Whitten, G. Z.: Final Report - Updates to the Carbon Bond Chemical Mechanism: CB05, Rep. RT-04-00675, Yocke and Co., Novato, CA, 246 pp., 2005.

Yarwood, G., Whitten, G. Z., Jung, J., Heo, G., and Allen, D. T.: Final Report - Development, Evaluation and Testing of Version 6 of the Carbon Bond Chemical Mechanism (CB6): Work Order No. 582-7-84005-FY10-26, ENVIRON, Novato, CA, 2010.

Yu, S., Eder, B., Dennis, R., Chu, S.-H., and Schwartz, S.: New unbiased symmetric metrics for evaluation of air quality models, Atmos. Sci. Lett., 7, 26-34, 2006.

Zhang, Q., Worsnop, D. R., Canagaratna, M. R., and Jimenez, J. L.: Hydrocarbon-like and oxygenated organic aerosols in Pittsburgh: insight into sources and processes of organic aerosols, Atmos. Chem. Phys., 5, 3289-3311, https://doi.org/10.5194/acp-5-32892005, 2005.

Zhang, Q., Jimenez, J. L., Canagaratna, M. R., Allan, J. D., Coe, H., Ulbrich, I., Alfarra, M. R., Takami, A., Middlebrook, A. M., Sun, Y. L., Dzepina, K., Dunlea, E., Docherty, K., DeCarlo, P. F., Salcedo, D., Onasch, T., Jayne, J. T., Miyoshi, T., Shimono, A., Hatakeyama, S., Takegawa, N., Kondo, Y., Schneider, J., Drewnick, F., Borrmann, S., Weimer, S., Demerjian, K., Williams, P., Bower, K., Bahreini, R., Cottrell, L., Griffin, R. J., Rautiainen, J., Sun, J. Y., Zhang, Y. M., and Worsnop, D. R.: Ubiquity and dominance of oxygenated species in organic aerosols in anthropogenically-influenced Northern Hemisphere midlatitudes, Geophys. Res. Lett., 34, L13801, https://doi.org/10.1029/2007GL029979, 2007.

Zhang, Q., Jimenez, J. L., Canagaratna, M. R., Ulbrich, I. M., Ng, N. L., Worsnop, D. R., and Sun, Y.: Understanding atmospheric organic aerosols via factor analysis of aerosol mass spectrometry: a review, Anal. Bioanal. Chem., 401, 3045-3067, https://doi.org/10.1007/s00216-011-5355-y, 2011.

Zhang, Y., Chen, Y.-C., Sarwar, G., and Schere, K.: Impact of gasphase mechanisms on WRF/Chem predictions: Mechanism implementation and comparative evaluation, J. Geophys. Res., 117, D01301, https://doi.org/10.1029/2011JD015775, 2012.

Zhang, Y., Zhang, X., Wang, K., He, J., Leung, L. R., Fan, J., and Nenes, A.: Incorporating an advanced aerosol activation parameterization into WRF-CAM5: Model evaluation and parameterization intercomparison, J. Geophys. Res.-Atmos., 120, 6952-6979, https://doi.org/10.1002/2014JD023051, 2015. 
Zhao, Y., Hennigan, C. J., May, A. A., Tkacik, D. S., de Gouw, J. A., Gilman, J. B., Kuster, W. C., Borbon, A., and Robinson, A. L.: Intermediate-volatility organic compounds: A large source of secondary organic aerosol, Environ. Sci. Technol., 48, 1374313750, https://doi.org/10.1021/es5035188, 2014.
Zheng, Y., Alapaty, K. A., Herwehe, J. A., Del Genio, A. D., and Niyogi, D.: Improving high-resolution weather forecasts using the Weather Research and Forecasting (WRF) Model with an updated Kain-Fritsch scheme, Mon. Weather Rev., 144, 833-860, https://doi.org/10.1175/mwr-d-15-0005.1, 2016. 